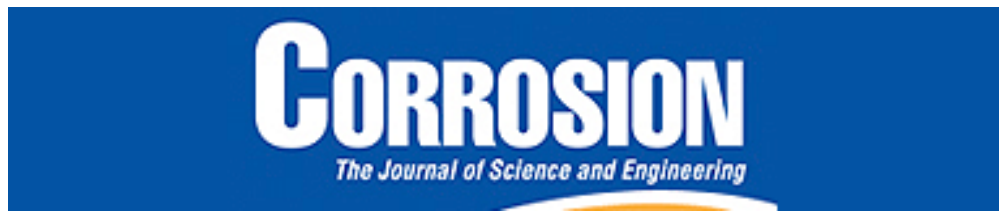

\title{
Towards a Physical Description of the Role of Germanium in Moderating Cathodic Activation of Magnesium
}

\begin{tabular}{|r|l|}
\hline Journal: & CORROSION \\
\hline Manuscript ID & CJ-2006-OA-3624.R1 \\
\hline Manuscript Type: & Original Article \\
\hline Author: & $\mathrm{n}$ (a) \\
\hline Complete List of Authors: & $\begin{array}{l}\text { Glover, Carol; University of Virginia, Materials Science Engineering } \\
\text { Liu, Ruiliang; Monash University, Materials Engineering } \\
\text { McNally, Beth; McMaster University, Department of Materials Science } \\
\text { and Engineering } \\
\text { Mahboubi, Shooka; Corrosion Service Company Limited, } \\
\text { McDermid, Joseph; McMaster, Materials Science \& Engineering } \\
\text { Kish, Joey; McMaster University, Materials Science \& Engineering } \\
\text { Birbilis, Nick; The Australian National University, College of Engineering } \\
\text { and Computer Science } \\
\text { McMurray, Neil; swansea university, engineering } \\
\text { Williams, Geraint; Swansea University, College of Engineering }\end{array}$ \\
\hline Key Words: & $\begin{array}{l}\text { magnesium, corrosion resistance, hydrogen evolution, alloying, } \\
\text { Transmission electron microscopy }\end{array}$ \\
\hline
\end{tabular}

\section{SCHOLARONE"


Towards a Physical Description of the Role of Germanium in Moderating Cathodic Activation of Magnesium

\author{
C.F.Glover*, R.L. Liu**, E.A. McNally ${ }^{* * *}$, S. \\ Mahboubi $^{* * *}$, J.R. McDermid ${ }^{* * *}$, J.R. Kish ${ }^{* * *}$, \\ N.Birbilis $^{* * * *}$, H.N. McMurray ${ }^{* * * * *}$, G.Williams ${ }^{* * * * *}$ \\ * Department of Materials Science and Engineering, \\ University of Virginia, Charlottesville, VA, 22904, USA
}

${ }^{* *}$ Department of Materials Science and Engineering, Monash University, Clayton, VIC, 3800, Australia

${ }^{* * *}$ Department of Materials Science and Engineering, McMaster University, Hamilton, ON Canada, L8S 4L7

${ }^{* * * *}$ College of Engineering and Computer Science, Australian National University, Acton, ACT, 2601, Australia.

${ }^{* * * * *}$ Materials Research Centre, College of Engineering, Swansea University, Bay Campus, Fabian Way, Swansea, UK, SA1 8EN.

Keywords:

A Magnesium

B Corrosion

C Anodic Dissolution

D SVET

E TEM

F Hydrogen Evolution

Center of Electrochemical Science and Engineering, Department of Materials Science and Engineering, University of Virginia, Charlottesville, VA 22904

Corresponding author:

Carol F. Glover

Telephone no: (434)-297-6737

Email: cfg3p@virginia.edu

48
51
52
53
54
55
56
57
58
59
60

\section{ABSTRACT}

The role played by surface film formation in moderating cathodic activation (i.e. $\mathrm{H}_{2}$ evolution associated with anodic dissolution in $\mathrm{NaCl}$ (aq)) was determined for an Mg-0.3Ge (wt\%) alloy and contrasted with this process in pure $\mathrm{Mg}$. Cathodic activation was not detected using the scanning vibrating electrode technique (SVET) during anodic dissolution of the Mg-0.3Ge alloy under either freely corroding or anodic polarization conditions. Filament tracks that initiated under the more aggressive testing condition remained electrochemically inert. However, volumetric $\mathrm{H}_{2}$ evolution measurements revealed that $\mathrm{Ge}$ alloying additions 'switch off' the remote cathodes observed on previously corroded pure $\mathrm{Mg}$ surfaces, while Ge additions did not eliminate the "local" cathode at the principal sites of anodic activity (which cannot be detected by SVET). As such, the quantity of $\mathrm{H}_{2}$ measured on the corroding $\mathrm{Mg}-0.3 \mathrm{Ge}$ alloy arises exclusively from cathodic $\mathrm{H}_{2}$ evolution at the anodic sites. Moderation of sustained cathodic activation by alloying with $\mathrm{Ge}$ was associated with the incorporation of $\mathrm{Ge}$ into the inner $\mathrm{MgO} / \mathrm{Mg}(\mathrm{OH})_{2}$ layer during anodic dissolution of $\mathrm{Mg}$. It is possible that entrapped $\mathrm{Ge}$ particles or $\mathrm{GeO}_{2}$ serve as an effective poison for $\mathrm{H}$ recombination in the overall $\mathrm{H}_{2}$ evolution reaction that would otherwise readily occur on freshly formed $\mathrm{Mg}(\mathrm{OH})_{2}$ at anodic dissolution sites.

\section{INTRODUCTION}

The corrosion of $\mathrm{Mg}$ and its alloys continues to limit their uptake as lightweight structural materials in industries that include automotive ${ }^{1}$ and electronics ${ }^{2,3,4}$. Recently, alloying approaches to moderate the corrosion of $\mathrm{Mg}$-alloys have been explored, including the group 14 and 15 elements, ${ }^{5,6,7}$ which may offer the prospect of moderating the rate of cathodic $\mathrm{H}_{2}$ evolution. The corrosion of $\mathrm{Mg}$ involves the anodic dissolution of $\mathrm{Mg}$ as the principle anode (Equation 1) coupled with $\mathrm{H}_{2}$ evolution as the principle cathode (Equation 2). Accumulation of dissolved $\mathrm{Mg}^{2+}$ cations and $\mathrm{OH}^{-}$anions at the interface eventually forms $\mathrm{Mg}(\mathrm{OH})_{2}$ via a dissolution-precipitation mechanism ${ }^{8}$ (Equation $3)$, once saturation is attained. Saturation results in a self-buffering effect such that the solution is maintained at an alkaline $\mathrm{pH}$ of, for example, 10.4 for a solubility product $\left(K_{s p}\right)$ of $1.24 \times 10^{-11} \mathrm{M}$ in $25^{\circ} \mathrm{C} 1$ $\mathrm{M} \mathrm{NaCl}(\mathrm{aq}) \cdot{ }^{9}$

$$
\begin{aligned}
& \mathrm{Mg}(\mathrm{s}) \rightarrow \mathrm{Mg}^{2+}(\mathrm{aq})+2 \mathrm{e}^{-} \\
& 2 \mathrm{H}_{2} \mathrm{O}+2 \mathrm{e}^{-} \rightarrow \mathrm{H}_{2}(\mathrm{~g})+2 \mathrm{OH}^{-}(\mathrm{aq}) \\
& \mathrm{Mg}^{2+}(\mathrm{aq})+2 \mathrm{OH}^{-}(\mathrm{aq}) \rightarrow \mathrm{Mg}(\mathrm{OH})_{2}(\mathrm{~s})
\end{aligned}
$$

Utilisation of the scanning vibrating electrode technique (SVET) has revealed that anodic dissolution of $\mathrm{Mg}$ in $\mathrm{NaCl}$ (aq) occurs locally, via a rather unique mode relative to other engineering alloys, that involves the formation of local anodes that traverse the exposed surface leaving behind dark tracks that serve as the necessary coupled cathodes. ${ }^{10,11}$ The local anode can propagate outwards either radially, or as a filament-like track from the breakdown site of the intact surface film, depending on the conductivity of the electrolyte and the concentration of noble metal (e.g. Fe) impurities. ${ }^{12,13}$ The ability of the dark regions left behind the propagating anode to serve as an active cathode, relative to the intact surface film, is the so-called cathodic activation that is observed both under freely-corroding and anodic polarization conditions. ${ }^{10-14,15}$

Cathodic activation in this context is the phenomenon whereby the cathodic reaction (typically $\mathrm{H}_{2}$ evolution) is enhanced by anodic dissolution. ${ }^{16}$ The mechanism responsible for the cathodic activation that accompanies anodic dissolution of $\mathrm{Mg}$ and its alloys continues to be debated. ${ }^{17}$ The general consensus involves the creation of an active cathode as a consequence of anodic dissolution (such as the bare dissolving surface itself), ${ }^{18}$ noble metal enrichment due to the selective dissolution of $\mathrm{Mg}^{19,20,21}$ or the re-deposition ${ }^{22,23}$ or formation of $\mathrm{Mg}(\mathrm{OH})_{2}$ as a corrosion product. ${ }^{24} \mathrm{~A}$ re-emerging alternative theory involves the formation and subsequent dissolution of $\mathrm{MgH}_{2}$, which releases $\mathrm{H}_{2}$ at the anodic dissolution site. ${ }^{25} \mathrm{An}$ important aspect of cathodic activation that has been determined from experimental testing to date is that, when significant noble-metal impurities are present, a major contribution to overall $\mathrm{H}_{2}$ evolution is made by "remote" cathodes, as detected by the SVET. However, on high purity (HP) $\mathrm{Mg}$ (i.e. having a low concentration of noble-metal impurities), the majority of $\mathrm{H}_{2}$ evolution has been argued to occur at the site of anodic dissolution, which is undetectable by the SVET. ${ }^{15}$ Micro-alloying Mg with Ge has been shown to reduce corrosion 
susceptibility in $\mathrm{NaCl}$ (aq) electrolytes by significantly inhibiting the global cathode $\left(\mathrm{H}_{2}\right.$ evolution) kinetics. ${ }^{5,6,7,26,27,28,29}$ Microscopic examination of the corroded surface in both plan-view and crosssectional view consistently reveals sites of discrete corrosion activity rather than features that traverse the surface. The discrete sites are confined to regions where a rod-shaped $\mathrm{Mg}_{2} \mathrm{Ge}$ intermetallic phase resides. Scanning Kelvin probe (SKP) measurements have shown that the $\mathrm{Mg}_{2} \mathrm{Ge}$ intermetallic phase has a more positive Volta potential than the $\alpha-M g$ matrix - i.e. $~+30 \mathrm{mV}$ more positive than the MgZn matrix ${ }^{29}$ and $\sim+400 \mathrm{mV}$ relative to the unalloyed $\mathrm{Mg}$ matrix. ${ }^{5}$ Thus, the intermetallic phase is posited to serve as a fixed active cathode (supporting $\mathrm{H}_{2}$ evolution, albeit rather sluggishly) in a micro-galvanic cell that involves the dissolution of the adjacent $\alpha-\mathrm{Mg}$ phase as the anode, with experimentally observed undercutting of the $\mathrm{Mg}_{2} \mathrm{Ge}$ phase as the supportive evidence. ${ }^{5,26,29}$ Such findings are significant as Ge represents an environmentally-friendly alternative to the more toxic As, which has generated interest due to its ability to effectively poison the cathodic reaction $\left(\mathrm{H}_{2}\right.$ evolution) on freely-corroding $\mathrm{Mg}^{30,31}$ and, thus, moderate cathodic activation. Such cathodic poisoning has been verified by the corrosion protection of $\mathrm{Mg}$ by the addition of As to the experimental electrolyte in soluble form. ${ }^{32}$

The underlying mechanism responsible for the ability of alloyed Ge to significantly inhibit the cathodic $\left(\mathrm{H}_{2}\right.$ evolution) kinetics has been given some consideration. An experimental survey designed to probe the susceptibility of pure $\mathrm{Ge}$ to cathodic activation in $\mathrm{NaCl}$ (aq) revealed no susceptibility, which was ascribed to the tendency of Ge to form an oxide, rather than a hydroxide, during anodic dissolution. ${ }^{33}$ The opencircuit potential (OCP) values measured in this study showed that pure $\mathrm{Ge}$ is significantly more noble than pure $\mathrm{Mg}$ when immersed in $\mathrm{NaCl}$ (aq). It follows that alloyed Ge and Ge-containing phases should be cathodically polarized under both freely corroding and anodic polarization conditions of Mg. Under such a situation, it has been proposed that inert Ge-containing particles may accumulate at anodic dissolution sites or could possibly be dislodged and redeposited at local cathode sites. ${ }^{28}$ This physical description is analogous to that proposed for the accumulation of inert noble metal (e.g. Fe) impurity particles, ${ }^{19,20,21}$ which serve to enhance cathodic activation. ${ }^{12,13,34}$. Inert Ge-containing particles could then serve as a cathode poison ${ }^{28}$ in a manner analogous to alloying transition metals with $\mathrm{As}, \mathrm{Sb}$ and $\mathrm{Sn}$, which reduced surface coverage of adsorbed $\mathrm{H}$ atoms and restricted the recombination of these atoms to form $\mathrm{H}_{2}$ molecules. ${ }^{35,36,37,38,39} \mathrm{On}$ a more atomistic scale, it has been proposed that alloyed Ge can effectively restrict the water-splitting reaction, which is a key initial step in the overall $\mathrm{H}_{2}$ evolution reaction. ${ }^{7}$

One aspect that has received little attention thus far is the role played by the surface film that forms during the anodic dissolution of $\mathrm{Mg}$ alloyed with Ge. A detailed examination of the composition and structure of the surface film that forms during anodic dissolution of $\mathrm{Mg}$ and its alloys has revealed key factors that contribute to cathodic activation. ${ }^{19,40,41}$ Cross-sectional elemental mapping of a corroded MgZnGe alloy after immersion in 0.9 wt.\% $\mathrm{NaCl}$ (aq) using scanning electron microscopy (SEM) coupled with $X$-ray energy dispersive spectroscopy (EDS) revealed the formation of an outer O-containing layer that was significantly enriched with Ge. ${ }^{29}$ However, no explanation was given linking this layer to the sluggish cathodic kinetics observed.

The objective of this work was to determine the role of the composition and/or structure of the local surface film formed during anodic dissolution on the sluggish cathodic $\left(\mathrm{H}_{2}\right.$ evolution) kinetics exhibited by $\mathrm{Mg}-0.3 \mathrm{Ge}$ (wt\%) (i.e. $\mathrm{Mg}-0.3 \mathrm{Ge}$ ) in $\mathrm{NaCl}(\mathrm{aq})$. Quantification of the influence of Ge on the moderation of sustained cathodic activation and the "negative difference effect" (NDE), ${ }^{18}$ i.e. the increase in the $\mathrm{H}_{2}$ evolution rate with increasing anodic polarization, were of particular interest. As such, SVET was employed to probe time-dependent localized corrosion activity of a Mg-0.3Ge alloy, relative to pure $\mathrm{Mg}$, in $\mathrm{NaCl}(\mathrm{aq})$. The structure and composition of the surface film formed at regions of interest after anodic polarization was examined by transmission electron microscopy (TEM) using cross-sectional samples prepared by focused ion beam (FIB) milling.

\section{EXPERIMENTAL}

\section{Materials}

Pure Mg (AmaC, Australia) and pure Ge (Alfa-Aesar, USA) were used to produce the $\mathrm{Mg}-0.3 \mathrm{Ge}$ (wt. \%) alloy. The alloy was melted and prepared in a Leybold-Heraeus ISO1/III induction furnace. Before melting, the induction furnace chamber was purged to a positive pressure (maintained slightly above $1 \mathrm{~atm}$ ) with the protective AM-cover ${ }^{\circledast}$ gas (10 wt. \% tetrafluoroethane - 90 wt. \% argon). A temperature of $750{ }^{\circ} \mathrm{C}$ was employed for melting, with the molten alloy contained in a steel crucible coated with graphite. The melt was subsequently held for $0.5 \mathrm{~h}$ with frequent stirring. Within the induction furnace chamber, the melt was cast into a preheated $\left(200^{\circ} \mathrm{C}\right)$ graphite-coated rectangular steel mould and allowed to cool naturally. Chemical analysis of the Mg-0.3Ge alloy was conducted independently by Spectrometer Services (Australia) using inductively coupled plasma atomic emission spectroscopy (ICPAES). The level of impurities (such as Fe) was shown to be below the "impurity threshold", as reported previously. ${ }^{5}$ The microstructure consisted of a primary $\alpha-\mathrm{Mg}$ matrix with a rod-shaped $\mathrm{Mg}_{2} \mathrm{Ge}$ intermetallic phase present along grain boundaries, also as reported previously. ${ }^{5}$ Control experiments were conducted using pure (99.99\%) $\mathrm{Mg}$, whose principal impurity elements were Fe (40 ppm), Ni (10 pm) and $\mathrm{Cu}(20 \mathrm{ppm})$.

\section{SVET measurements}

Prior to all SVET analyses, all pure $\mathrm{Mg}$ and Mg-0.3Ge alloy specimens were abraded using successive grades of SiC paper, followed by polishing with a $5 \mu \mathrm{m}$ aqueous alumina slurry. Specimens were then washed with an aqueous surfactant and rinsed using ethanol. SVET experiments were conducted in both freely corroding (i.e. unpolarized) and under anodic polarization conditions. The vibrating probe in the SVET consisted of a $125 \mu \mathrm{m}$ Pt wire (Goodfellow Ltd.) sealed in a glass sheath giving a total diameter of $250 \mu \mathrm{m}$. A complete description of the design and calibration procedure for the SVET instrument is available elsewhere. ${ }^{10}$ For each experiment, the working surface of the specimen was fully immersed in an electrolyte bath comprising $\mathrm{NaCl}(\mathrm{aq})$ at concentrations ranging from $0.1 \mathrm{M}$ to $2 \mathrm{M}$ at a temperature of $20^{\circ} \mathrm{C}$ and $\mathrm{pH}$ 6.5. The vibrating probe was positioned vertically and scanned at a constant height of $100 \mu \mathrm{m}$ above the working surface. In the case of the anodically-polarized specimens, current density values in the range +1 to $+4 \mathrm{mAcm}^{-2}$ were applied via an in-house micro-galvanostat, where a Pt gauze was used as the counter electrode. Initiation of polarization was applied after a ten minute immersion period at the OCP and scanning of the working surface was carried out immediately upon immersion and at intervals of 300 seconds ( 5 minutes) thereafter for periods of up to 3 hours. Experiments were carried out in triplicate.

\section{Gravimetric $\mathrm{H}_{2}$ Evolution Measurements}

All working surfaces were ground to a 1200 grit surface finish using SiC abrasive papers and sonicated in ethanol prior to $\mathrm{H}_{2}$ collection testing. Surfaces were completely sealed using PTFE tape, leaving an exposed $\sim 5$ $\mathrm{cm}^{2}$ working surface area. An inverted burette with a funnel diameter much larger than the specimen immersed in $0.1 \mathrm{M} \mathrm{NaCl}$ (aq) was used for $\mathrm{H}_{2}$ collection. $\mathrm{H}_{2}$ was measured while specimens were held under galvanostatic anodic polarization in the range of +1 to $+4 \mathrm{mAcm}^{-2}$. Experiments were carried out in triplicate. 


\section{Surface film TEM examination}

A small specimen of the Mg-0.3Ge alloy was cold-mounted in epoxy with a coated $\mathrm{Cu}$ wire attached to the back face to create a working electrode for potentiostatic anodic polarization and associated surface film formation experiments. The working surface was mechanically-abraded to a 4000 grit surface finish using SiC abrasive papers using an ethylene glycol-ethanol mixture as a lubricant, after which the sample was rinsed with ethanol and dried using an air steam. A conventional $1000 \mathrm{~mL}$ three electrode electrochemical cell and a Gamry Reference 600 potentiostat were used for anodic polarization. A graphite rod served as the counter electrode and a saturated calomel electrode (SCE) served as the reference electrode. The electrolyte was $0.01 \mathrm{M} \mathrm{NaCl}$ (aq), which was naturally-aerated at room temperature. The working surface was conditioned at the OCP for 24 hours prior to anodic polarization at +100 $\mathrm{mV}$ more positive than the OCP for 0.5 hours. Potentiostatic, rather than galvanostatic, polarization was chosen here to be consistent with the procedure used to produce an anodic surface film on pure $\mathrm{Mg}$ (40 ppm $\mathrm{Fe}$ ) in $\mathrm{NaCl}(\mathrm{aq})$ for comparison purposes. ${ }^{19}$

Following potentiostatic anodic polarization, the specimen was carefully removed from the epoxy mount, and focused ion beam (FIB) milling was employed to produce two cross-sectional TEM specimens which were subsequently mounted on a CU TEM grid: one specimen from the intact surface film excised from the centre of a grain, and another specimen from a grain boundary region that exhibited preferential anodic dissolution. Once the sites of interest were chosen, a $\mathrm{W}$ layer was deposited on top of the surface films to protect against damage during ion milling. FIB milling was carried out using a $\mathrm{Ga}^{+}$beam with an initial acceleration voltage of $30 \mathrm{keV}$, which was then gradually reduced to 1 $\mathrm{keV}$ during the final stages of sample preparation to minimize ion damage. FIB milling was conducting using a NVision 40 CrossBeam $^{\circledR}$ Workstation. The electron transparent specimens were examined using a FEI Titan 80-300 LB TEM operated at $300 \mathrm{keV}$ equipped with energy dispersive X-ray spectroscopy (EDS, Oxford Inca, Si(Li) detector) with a cryogenic stage used to maintain the sample temperatures near $-178^{\circ} \mathrm{C}$ in order to minimize electron beam damage. Selected area diffraction (SAD) patterns were acquired from $210 \mathrm{~nm}$ diameter regions of interest and were indexed using data from the ICSD (inorganic crystal structure database) for crystal structure identification. Scanning TEM (STEM)-EDS was used in the high angle annular dark field (HAADF) mode to spatially map the surface film elemental distribution with a focus on $\mathrm{Mg}, \mathrm{Ge}$, and $O$. Analysis of the STEM-EDS data was done using the commercial INCA (Oxford Instruments) software.

\section{Results}

\section{Anodic Dissolution on Pure Mg and Mg-0.3Ge under freely corroding conditions}

An SVET-derived surface current density map, acquired along the axis of probe vibration $\left(\mathrm{j}_{\mathrm{z}}\right)$, for the freely corroding pure $\mathrm{Mg}$ after 9 hours of immersion $0.1 \mathrm{M} \mathrm{NaCl}(\mathrm{aq})$ solution is given in Figure 1a.i. The map reveals two intense local anodic sites (dark red) coupled with cathodically-activated (dark blue) regions that extend across the surface in the form of tracks. These tracks correspond to the dark regions (filaments) that are visible in the photographic image (Figure 1a.ii), taken after 9 hours of immersion. As reported by prior SVET measurements using the same material (pure $\mathrm{Mg}$ ), ${ }^{12,30}$ these tracks are left in the wake of the intense focal anodes as they traverse the inert (white) regions corresponding to the intact MgO surface film. In stark contrast, no corrosion activity was observed on the surface of the Mg$0.3 \mathrm{Ge}$ alloy during the an extended 90 hours of immersion in $0.1 \mathrm{M} \mathrm{NaCl}$ (aq) solution under otherwise identical conditions. An SVET-derived surface current density map for Mg-0.3 Ge after 9 hours of immersion is shown in Figure 1b.i. The map, typical of all those acquired throughout the experiment, reveals extremely low current density values measured above the surface. The photographic image presented in Figure 1b.ii was taken after removal from solution after 90 hours of immersion and shows a dull surface with no visual signs of localized corrosion.

Representative area-averaged, time-dependent integrated anodic current density $\left(i_{a}\right)$ values for both pure $\mathrm{Mg}$ and $\mathrm{Mg}-0.3 \mathrm{Ge}$ exhibited during immersion in $0.1 \mathrm{M} \mathrm{NaCl}(\mathrm{aq})$ are given in Figure 2. The initial corrosion activity was low for pure $\mathrm{Mg}$ until approximately 2 hours, after which values of $\geq+0.1 \mathrm{Am}^{-2}$ were measured, gradually increasing to ca. $+0.2 \mathrm{Am}^{-2}$ by 9 hours. For Mg-0.3Ge, consistently low current density values of ca. $+0.03 \mathrm{Am}^{-2}$ were measured throughout the 90-hour immersion, in agreement with the lack of visual signs of corrosion found on the surface (Figure 1b.ii).

Further experiments were carried out to determine if increased chloride concentrations would induce breakdown (localized corrosion) of $\mathrm{Mg}$ $0.3 \mathrm{Ge}$. Figure 3 gives a summary of the area-averaged, time-dependent integrated current density $\left(\mathrm{J}_{\mathrm{a}}\right)$ values for $\mathrm{Mg}-0.3 \mathrm{Ge}$, acquired during immersion in $\mathrm{NaCl}(\mathrm{aq})$ solution with $\mathrm{NaCl}$ concentrations of $0.1 \mathrm{M}, 0.5$ $\mathrm{M}, 1 \mathrm{M}$ and $2 \mathrm{M}$ at $\mathrm{pH} 7$ for 9 hours. No breakdown was observed in 0.5 $\mathrm{M} \mathrm{NaCl}(\mathrm{aq})$ and a $\mathrm{J}_{\mathrm{a}}$ value of ca. $0.03 \mathrm{Am}^{-2}$ was consistently measured throughout the 9-hour immersion. It is evident from the plots for the 1 $\mathrm{M}$ and $2 \mathrm{M} \mathrm{NaCl}$ (aq) concentrations that, after an electrochemically inactive initial period of about 2 hours, breakdown occurred, as denoted by the sharp rise in $\mathrm{J}_{\mathrm{a}}$ that was maintained at ca. $0.35 \mathrm{Am}^{-2}$ for both the $1 \mathrm{M}$ and $2 \mathrm{M}$ chloride electrolytes. This is an order of magnitude lower than that measured previously for pure Mg under the same conditions. ${ }^{30}$ Figures $4 \mathrm{a}$ and $4 \mathrm{~b}$ show representative SVET-derived surface current density maps for pure $\mathrm{Mg}$ and $\mathrm{Mg}-0.3 \mathrm{Ge}$, respectively, from scans carried out in $2 \mathrm{M} \mathrm{NaCl}(\mathrm{aq})$ at $\mathrm{pH}$ 7. Corrosion of pure $\mathrm{Mg}$ progressed in a manner identical to that observed in $0.1 \mathrm{M} \mathrm{NaCl}$ (aq) (Figure 1a.ii). A track of cathodic activity followed an intense focal anode that traversed the exposed surface (Figure 4a.i-a.iii), leaving behind the dark filaments pictured in the photographic image given in Figure 4a.iv.

For the Mg-0.3Ge specimen, slightly different corrosion activity was observed under identical conditions. A cluster of intense focal anodes were found to traverse the exposed surface, as with pure Mg. However, the focal anode track did not show cathodic activity with respect to the intact surface, which itself served as a low current density distributed cathode (Figure 4b.i-b.iii). Furthermore, the intense focal anodes observed on Mg-0.3Ge remained sites of visible $\mathrm{H}_{2}$ evolution, despite their appearance as net local anodes, as detected by the SVET. It should be noted that the SVET cannot resolve local cathodic $\mathrm{H}_{2}$ evolution currents $\left(I_{c}\right.$ local $)$ emerging from the principal sites of $\mathrm{Mg}$ anodic dissolution (i.e. the net anodes), because the lines of ionic current flux coupling these reactions pass under the scan plane and so remain undetected. ${ }^{15,42}$ However, what the SVET can quantify is the cathodic current due to cathodes that are spatially distanced from local anodes by distances that are greater than the scan height $\left(I_{c, \text { remote }}\right)$. Thus, the total cathode $\left(\mathrm{H}_{2}\right.$ evolution) current $\left(\mathrm{I}_{c, \text { total }}\right)$ is given by: ${ }^{5}$

$I_{c, \text { total }}=I_{c, \text { local }}+I_{c, \text { remote }}$

However, the magnitude of $\mathrm{I}_{\mathrm{c}, \text { local }}$ can be estimated if both SVET and volumetric $\mathrm{H}_{2}$ evolution experiments are carried out on the same specimen (i.e. $I_{c, \text { local }}=I_{c \text {,total }}-I_{c \text {,remote }) .}{ }^{15}$ In other words, subtracting the integrated SVET cathodic current from the total cathodic current estimated from volumetric $\mathrm{H}_{2}$ evolution measurements. The observations made here suggest that, while (local) cathodic activation clearly persists at the site of $\mathrm{Mg}$ anodic dissolution, $\mathrm{Ge}$ is highly effective at de-activating (remote) cathodic $\mathrm{H}_{2}$ evolution at the sites of prior $\mathrm{Mg}$ anodic dissolution, such that the associated track is inert within the 300 $\mathrm{s}$ (5 minutes) required to complete an individual SVET scan of the 
surface. The visual appearance of the tracks (filaments in Figure 4b.iv) also differs from the typical dark filaments found on pure Mg (Figure 4a.iv) and can be seen to be white/grey appearance.

OCP transients, given in Figure 5, demonstrate a suppression of the OCP for $\mathrm{Mg}-0.3 \mathrm{Ge}$ in comparison to pure $\mathrm{Mg}$. A relatively consistent value of ca. $-1.68 \mathrm{~V}_{S C E}$ is exhibited by pure $\mathrm{Mg}$ in $2 \mathrm{M} \mathrm{NaCl}(\mathrm{aq})$, while, for $\mathrm{Mg}$ $0.3 \mathrm{Ge}$, an initial value of ca. $-1.94 \mathrm{~V}_{\text {SCE }}$ was established that gradually increased to $-1.825 \mathrm{~V}_{\text {SCE }}$ over a $1 \mathrm{~h}$ period. This represents an extended relative chemical stability of the intact surface film by sustaining an OCP that is more negative than the nominal breakdown potential $\left(E_{b}\right)$ of pure $\mathrm{Mg}$ (i.e. approximately $-1.6 \mathrm{~V}$ vs. SCE in aqueous $2 \mathrm{M} \mathrm{NaCl}^{43}$ ). Breakdown did not occur over protracted periods of immersion in $0.1 \mathrm{M} \mathrm{NaCl}(\mathrm{aq})$. At higher concentrations, i.e. $1 \mathrm{M} \mathrm{NaCl}(\mathrm{aq})$, this does not hold because $E_{b}$ is a function of $\log \left[\mathrm{Cl}^{-}\right]$and becomes more negative as $\left[\mathrm{Cl}^{-}\right]$is increased. ${ }^{44}$

\section{Anodic dissolution of Pure $\mathrm{Mg}$ and $\mathrm{Mg}-0.3 \mathrm{Ge}$ under anodic polarization}

The SVET-derived surface current density maps given in Figure 6a.i-c.i show 'snap-shots' of the electrochemical activity exhibited by pure $\mathrm{Mg}$ when fully immersed in $0.1 \mathrm{M} \mathrm{NaCl}(\mathrm{aq})$ at applied anodic current density ( $\left.i_{\text {applied }}\right)$ values of $+1 \mathrm{mAcm}^{-2},+2 \mathrm{mAcm}^{-2}$ and $+4 \mathrm{mAcm}^{-2}$, respectively. Upon application of $i_{\text {applied }}$ a very limited window of chemical stability was observed prior to the onset of localized breakdown, which was characterized initially by the physical appearance of dark spots, which corresponded to intense local anodes, as detected by the SVET. From these dark spots, dark filaments emerged and lengthened over time, where, as detected by the SVET, the leading edge was sustained as an intense focal anode, coupled with a cathodically-activated track left in its wake. In all cases, cathodes were detected by the SVET, albeit with decreasing intensity and area coverage with increasing $i_{\text {applied. }}$ The partially-dissolved surfaces shown in part ii of Figure 6a-c were removed from the electrolyte prior at 76 minutes, full coverage of the exposed surface was shown previously to occur at exposure times in excess of 80 minutes. ${ }^{14}$ The cathodic tracks revealed by the current density maps correspond to the dark filaments on the exposed surface in Figure 6aii, this is more difficult to distinguish in Figures6b-c.

Previous investigations conducted in the $+0.4 \mathrm{mAcm}^{-2}$ to $+2 \mathrm{mAcm}^{-2}$ $\mathrm{i}_{\text {applied }}$ range demonstrated that the rate of surface coverage by the dark cathodically-activated filaments on pure $\mathrm{Mg}$ occurred at a faster rate than was observed without anodic polarization (open-circuit conditions) and this rate increased progressively with increasing $\mathrm{i}_{\text {applied. }}{ }^{30}$ In the same investigation, SVET-derived integrated current, I (A), measured as a function of time, revealed that the anodic current $\left(I_{a}\right)$ emerging from the pure $\mathrm{Mg}$ surface increased in proportion to the cathodic current $\left(I_{c}\right) \cdot{ }^{30}$ Furthermore, the trends established at the various galvanostatic $i_{\text {applied }}$ values (Figure 6 ) correlate well with the trends observed in the gravimetric $\mathrm{H}_{2}$ evolution measurements that are presented below. This provides evidence that the $\mathrm{H}_{2}$ evolution from the dissolving $\mathrm{Mg}$ anode originates at a local cathode and, as a result, $\mathrm{Mg}$ dissolves in much larger quantities than would be predicted when considering the SVET-derived net charge passed. ${ }^{11}$ This is consistent with the observations in Figure 7, which shows a plot of the time dependent SVET-derived integrated anodic and cathodic current $\left(I_{a}\right.$ and $\left.I_{c}\right)$, respectively, normalized for a 1 $\mathrm{cm}^{2}$ surface of pure $\mathrm{Mg}$ held under galvanic anodic polarization at +1 $\mathrm{mAcm}^{-2}$ in $0.1 \mathrm{M} \mathrm{NaCl}(\mathrm{aq})$. Both $\mathrm{I}_{\mathrm{a}}$ and $\mathrm{I}_{\mathrm{c}}$ increased progressively with increasing time and $I_{a}$ is greater than the $i_{\text {applied }}$ value (denoted by the horizontal dashed line at $1 \mathrm{~mA}$ ).

Experiments were conducted under identical conditions to determine the efficiency of alloyed Ge in moderating the cathodic activation of a dissolving Mg surface under anodic polarization. SVET-derived surface current density maps are given in Figure 8 for $\mathrm{Mg}-0.3 \mathrm{Ge}$ under galvanostatic anodic polarization of $+1 \mathrm{mAcm}^{-2},+2 \mathrm{mAcm}^{-2}$ and +4
$\mathrm{mAcm}^{-2}$ in $0.1 \mathrm{M} \mathrm{NaCl}(\mathrm{aq})$. At $\mathrm{i}_{\text {applied }}=+1 \mathrm{mAcm}^{-2}$, the entire exposed surface was a large anode with $j_{z}$ values in the range +10 to $+15 \mathrm{Am}^{-2}$ (Figure 8a.i - a.ii). There was no deviation from this range of values throughout the $3 \mathrm{~h}$ experiment. Remote cathodic sites were not detected. Furthermore, the physical appearance of the exposed surface upon removal from solution showed no sign of any dark filament formation, only a small amount of white tarnishing (Figure a.iii). This suggests that the Mg- $0.3 \mathrm{Ge}$ alloy is capable of withstanding breakdown while under anodic polarization at $+1 \mathrm{mAcm}^{-2}$, albeit for the short immersion times considered.

At higher $\mathrm{i}_{\text {applied }}$ values of $\geq+2 \mathrm{mAcm}^{-2}$ (Figure $8 \mathrm{~b}$ and $8 \mathrm{c}$ ) the surface current density maps reveal a series of highly focal anodic sites with peak $j_{z}$ values of $+100 \mathrm{Am}^{-2}$, which increased in magnitude over time. These sites were mobile, but no remote cathodic sites were detected by the SVET throughout the $3 \mathrm{~h}$ immersion. This is also shown by the areaaveraged integrated $I_{a}$ and $I_{c}$ transients plotted in Figure 7 for galvanostatic anodic polarization at $+1 \mathrm{mAcm}^{-2}$, where the $I_{c}$ is zero for the entire duration and $l_{a}$ remains at or below $+1 \mathrm{~mA}$. It is apparent, however, from the photographic images of the post-immersion exposed surface given in Figure 8b.iii and 8c.iii that a dark film formed over the entire surface. The results presented here suggest that the $\mathrm{Mg}-0.3 \mathrm{Ge}$ alloy is able to deactivate cathodic activation of this dark film, even under anodic polarization.

\section{$\mathrm{H}_{2}$ evolution measurements on $\mathrm{Mg}$ and $\mathrm{Mg}-0.3 \mathrm{Ge}$}

Figure 9 presents a plot of the total moles of $\mathrm{H}_{2}$ evolved vs. time for $\mathrm{Mg}$ $0.3 \mathrm{Ge}$ under a galvanostatic anodic polarization regime of $+4 \mathrm{mAcm}^{-2}$, $+2 \mathrm{mAcm}^{-2}$ and $+1 \mathrm{mAcm}^{-2}$ when immersed in $0.1 \mathrm{M} \mathrm{NaCl}$ (aq). Also included is the data for a pure $\mathrm{Mg}$ under a galvanostatic anodic polarization of $+1 \mathrm{mAcm}^{-2}$ in the same electrolyte. While some $\mathrm{H}_{2}$ is evolved from $\mathrm{Mg}-0.3 \mathrm{Ge}$, the amount is reduced to a third of that produced by pure $\mathrm{Mg}$ (i.e. $0.008 \mathrm{~mol} \mathrm{~m}^{-2}$ and $0.024 \mathrm{~mol} \mathrm{~m}^{-2}$, respectively) for the experiment carried out at $+1 \mathrm{mAcm}^{-2}$. As demonstrated previously, evolved $\mathrm{H}_{2}$ originates from the cathode(s) that are co-located at the local anode sites, ${ }^{11}$ but are not detectable by SVET as the anode-cathode spacing is smaller than the probe height. ${ }^{15}$ For $\mathrm{Mg}-0.3 \mathrm{Ge}, \mathrm{I}_{\mathrm{c} \text {, local }}$ (Equation 4 ) can be assumed to be equal to $\mathrm{I}_{\mathrm{c} \text {,total }}$ because no cathodic activity was detected by the SVET that would account for any contribution from $I_{c, \text { remote. }}$. The change in $I_{c, \text { local }}$ provided by alloying $\mathrm{Ge}$ to $\mathrm{Mg}$ can be quantified by comparison with $\mathrm{I}_{\mathrm{c} \text {,local }}$ for pure $\mathrm{Mg}$. The latter can be calculated by subtracting $I_{c, \text { remote }}$ (determined by the SVET measurements) from $\mathrm{I}_{\mathrm{c} \text {,total }}$ (determined by gravimetric $\mathrm{H}_{2}$ evolution measurements). $I_{c, \text { total }}$ can be calculated using ${ }^{15}$

$I_{T}=\frac{d V_{H_{2}}}{d t} \times \frac{P}{R T} \times 2 F$

where $V_{H_{2}}$ is the total volume of $\mathrm{H}_{2}$ measured volumetrically, $\mathrm{t}$ is time, $\mathrm{P}$ is atmospheric pressure, $\mathrm{R}$ the ideal gas constant, $\mathrm{T}$ the temperature and $\mathrm{F}$ is Faraday's constant. Using Equation 5 and subtracting the SVETderived $I_{c, \text { remote }}$ contribution for pure $\mathrm{Mg}, I_{\text {c,local }}$ values of $-0.023 \mathrm{Am}^{-2}$ and $-0.006 \mathrm{Am}^{-2}$ were obtained for pure $\mathrm{Mg}$ and $\mathrm{Mg}-0.3 \mathrm{Ge}$, respectively. As such, a $73 \%$ reduction in the quantity of $\mathrm{H}_{2}$ evolved is estimated.

\section{Anodic surface film characterization of $\mathrm{Mg}-0.3 \mathrm{Ge}$}

Figure 10a shows a typical SEM secondary electron image (SEM-SEI) of the Mg-0.3Ge surface after 1 hour of conditioning at the OCP in $0.01 \mathrm{M}$ $\mathrm{NaCl}$ (aq) solution. The network distribution of the rod-shaped $\mathrm{Mg}_{2} \mathrm{Ge}$ intermetallic phase, present along grain boundaries, is clear. Upon closer inspection of the grain boundary region, it is also apparent that localized corrosion of the matrix in the region adjacent to the $\mathrm{Mg}_{2} \mathrm{Ge}$ intermetallic network occurred. Figure 10b shows a typical SEM-SEI image of the Mg-0.3Ge surface after an additional anodic polarization at 
$+100 \mathrm{mV}$ more positive than the OCP for 0.5 hours. The preferential dissolution of the matrix in the region adjacent to the $\mathrm{Mg}_{2} \mathrm{Ge}$ intermetallic phase network was significantly enhanced under anodic polarization. This is the only region where significant anodic dissolution was observed. In other words, evidence of localized anodic dissolution of the matrix phase, away from the grain boundary regions, was not observed. The red horizontal lines superimposed onto the image identify the regions of the anodically-polarized surface from which TEM specimens were excised and prepared using FIB milling. Thus, one specimen was extracted from the center of a grain that was not preferentially dissolved, whereas the other was extracted from a grain boundary region that was preferentially dissolved.

Figures 11 and 12 show a bright field image of the surface film formed on the center region of a grain ( $\alpha-\mathrm{Mg}$ matrix phase) and the preferentially dissolved grain boundary region, respectively. The film formed on the $\alpha-\mathrm{Mg}$ matrix phase is relatively uniform and compact ( $250 \mathrm{~nm}$ thick). It consists of two layers: a somewhat thicker, granular inner layer and a somewhat thinner outer columnar layer. Defects such as cracks and pores were not observed, at least at the length scales considered. Superimposed onto the bright field image in Figure 11 are two circles corresponding to regions from which an SAD pattern was acquired: one centered on the inner layer and the other centered on the outer layer. The associated SAD patterns are also shown in Figure 11. Both layers are mixtures of $\mathrm{Mg}(\mathrm{OH})_{2}$ and $\mathrm{MgO}$, with $\mathrm{MgO}$ diffraction occurring uniformly as rings in the SAD pattern and $\mathrm{Mg}(\mathrm{OH})_{2}$ diffraction occurring as spots on the rings. The former is characteristic of a nanocrystalline, non-oriented $\mathrm{MgO}$ and the latter indicates a more preferred orientation or fewer crystals of $\mathrm{Mg}(\mathrm{OH})_{2}$ in each selected region.

The film formed on the preferentially-dissolved grain boundary region (Figure 12) is shown to be substantially more defective as it contained significant populations of crack-like features (bright regions in the bright field image in Figure 12). Horizontal crack-like features are present in the film formed on the $\alpha-M g$ matrix phase in the region adjacent to the grain boundary, in addition to being present within the metal itself, having initiated from the grain boundary. The walls of these metalpenetrating crack-like features were covered with a film. The bi-layer film formed on the $\alpha$-Mg matrix is somewhat thicker than that formed in the region adjacent to the grain boundary. The film formed on the crack walls consisted of a single compact, granular layer. Superimposed onto the bright field image are two circles corresponding to regions from which an SAD pattern was acquired: one centered on the granular inner layer of the film formed on the $\alpha-M g$ matrix phase adjacent to the grain boundary and the other centered on the granular layer formed on the wall for a metal-penetrating crack. The associated SAD patterns are shown in Figure 12. Again, both granular layers comprised mixtures of $\mathrm{Mg}(\mathrm{OH})_{2}$ and $\mathrm{MgO}$, with $\mathrm{MgO}$ diffraction occurring uniformly as rings in the SAD pattern and $\mathrm{Mg}(\mathrm{OH})_{2}$ diffraction occurring as spots on the rings. Rings or spots associated with $\mathrm{GeO}_{2}$ were not detected in the regions characterized in Figures 11 or 12.

A cross-sectional HAADF-STEM dark field image and an associated set of STEM-EDS elemental maps of $\mathrm{O}, \mathrm{Mg}$, and $\mathrm{Ge}$ of the surface film formed on the $\alpha-M g$ matrix phase sample excised from the grain center (Figure $10 \mathrm{~b}$ ) is shown in Figure 13. The frame superimposed on the dark field HAADF-STEM image (Figure 12a) is shown to facilitate cross-correlation of the elemental maps with the film microstructure. $\mathrm{Mg}$ is depleted in the film relative to the metal, whereas $O$ is enriched. Interestingly, the outer columnar layer is richer in $\mathrm{Mg}$ than the granular inner layer. Of particular interest is the enrichment of $\mathrm{Ge}$ in the granular inner layer. A supplemental depth profile plot is given in Figure 14 to demonstrate this more clearly. Ge (at.\%) across the inner/outer layers is shown. Data were obtained using the STEM-EDS data in the elemental maps shown in Figure 13. The Ge map from the STEM-EDS of the oxide/hydroxide is poorly defined because the Ge concentration is very small and the beam scanning time per pixel (dwell time) was required to be very short (on the order of a few seconds) to prevent damage and pores in the TEM sample. The large superimposed frame in the HAADF-STEM image is the region that was mapped using EDS, whereas the small superimposed frame is the granular inner layer that comprised $\mathrm{Mg}$, $\mathrm{Ge}$ and $\mathrm{O}$ and major film-forming elements. As EDS only gives elemental, not chemical (oxidation state), identification, more research utilizing a technique such as electron energy loss spectroscopy (EELS) is required to delineate the oxidation state of Ge within the granular layer, as formed on both the $\alpha-M g$ matrix and all of the crack-like features.

\section{Discussion}

The objective of this work was to determine the role of the alloy composition and/or structure of the local surface film formed during anodic dissolution on the sluggish cathodic kinetics, and the moderation of cathodic activation in particular, exhibited by $\mathrm{Mg}-0.3 \mathrm{Ge}$ in $\mathrm{NaCl}(\mathrm{aq})$ solution. It is clear from the SVET investigation and the gravimetric $\mathrm{H}_{2}$ evolution measurements (Figure 9) that $\mathrm{Mg}-0.3 \mathrm{Ge}$ is effective in significantly moderating the cathodic activation (both remotely and locally) of $\mathrm{Mg}$ during anodic dissolution in $\mathrm{NaCl}(\mathrm{aq})$ solution under external polarization (Figures 6-8), in addition to freely corroding conditions (Figures 1-4). In this work, cathodic activation of $\mathrm{Mg}-0.3 \mathrm{Ge}$ was only observed visually under freely corroding condition in $\mathrm{NaCl}(\mathrm{aq})$ with a concentration exceeding $1 \mathrm{M}$, as the intense focal anodes that formed in these electrolytes remained sites of visible (local) $\mathrm{H}_{2}$ evolution, despite their appearance as net local anodes as revealed by the SVET (Figure 4b).

Inspection of the pre-polarised $\mathrm{Mg}-0.3 \mathrm{Ge}$ surface in $0.01 \mathrm{M} \mathrm{NaCl}(\mathrm{aq})$ for $1 \mathrm{~h}$ at the OCP (Figure 10a) revealed that sites of discrete corrosion occurred locally, in regions adjacent to the $\mathrm{Mg}_{2} \mathrm{Ge}$ intermetallic network. This observation is consistent with prior work on Mg-Ge alloys, where corrosion occurs locally adjacent to the $\mathrm{Mg}_{2} \mathrm{Ge}$ intermetallic phase network. $5,6,7,26,27,28,29$ The lack of spatially-resolved anodic and cathodic activity associated with the presumed micro-galvanic cell activity,26,29 in the SVET-derived current density maps for the freely corroding $\mathrm{Mg}-0.3 \mathrm{Ge}$ in $<1 \mathrm{M} \mathrm{NaCl}$ (aq) conditions (Figure 1b) is consistent with the rather small length-scale over which such microgalvanic activity occurs. ${ }^{15,42}$ The key question here is why cathodic activation is not triggered by the initiation of anodic dissolution. The answer may reside with the surface film that forms on the sites of anodic dissolution, as will be discussed in some detail below.

The TEM examination revealed the formation of a surface film on Mg$0.3 \mathrm{Ge}$ under anodic polarization after conditioning at the OCP, both on the surface of the $\alpha-\mathrm{Mg}$ matrix away from the discrete localized corrosion (Figure 11) and on the walls of the crack-like features associated with the discrete localized corrosion (Figure 12). Common to both films is the formation of a granular layer that resides directly on the metal surface. The STEM-EDS analysis of the granular layer residing on the $\alpha-\mathrm{Mg}$ matrix reveals that $\mathrm{Ge}$ is enriched in this layer relative to the metal. The Ge EDS map in Figure 13 suggests that the enrichment is uniform, not localized, within this layer. As mentioned earlier, the chemical state of $\mathrm{Ge}$ in this layer cannot be deduced from STEM-EDS analysis. Thus, two options are possible: (1) the Ge enrichment can be inert Ge particles that are incorporated into the $\mathrm{MgO} / \mathrm{Mg}(\mathrm{OH})_{2}$ inner layer that forms from the selective dissolution of $\mathrm{Mg}$ from the $\alpha-\mathrm{Mg}$ matrix or (2) it can be $\mathrm{Ge}^{4+}$ cations incorporated into the $\mathrm{MgO} / \mathrm{Mg}(\mathrm{OH})_{2}$ film that formed from anodic dissolution. Either pathway is consistent with the global anode that was revealed by the SVET measurements on the $\mathrm{Mg}-0.3 \mathrm{Ge}$ surface under anodic polarization at $+1 \mathrm{mAcm}^{2}$ in $0.1 \mathrm{M}$ $\mathrm{NaCl}$ (aq) (Figure 8a). The global anodic activity also tends to discount a redeposition of dissolved Ge at local cathode sites since no cathodic current was detected by the SVET investigation under these conditions. Figure 15 plots the $\mathrm{O} / \mathrm{Mg}$ atomic ratio as a function of distance across the film/metal interface using the STEM-EDS data in the elemental maps shown in Figure 13. Also included in Figure 15, for comparative purposes, is published data for a region that exhibited cathodic 
activation on commercially pure $\mathrm{Mg}$ under an anodic polarization of $+100 \mathrm{mV}$ vs. the OCP in $0.1 \mathrm{M} \mathrm{NaCl}$ (aq) solution, which is discussed later. ${ }^{19}$ The film/metal interface is well defined by the significant increase in the $\mathrm{O} / \mathrm{Mg}$ ratio over a rather short distance. There are two distinct regions within the film based on relative changes in the $\mathrm{O} / \mathrm{Mg}$ ratio, which is consistent with the bi-layer structure revealed through direct imaging. The inner (granular) layer shows an $\mathrm{O} / \mathrm{Mg}$ ratio of about 3 , whereas the outer (columnar) layer exhibits a ratio of about 2 . Thus, despite the SAD results indicating that both layers comprised of $\mathrm{MgO} / \mathrm{Mg}(\mathrm{OH})_{2}$ (Figure 12), it is likely that the inner layer contains another compound that is responsible for increasing the $\mathrm{O}$ content relative to $\mathrm{Mg}$ content. Given that Ge was found to be enriched in the inner layer (Figure 13), a simple explanation involves the incorporation of $\mathrm{GeO}_{2}$ (hence the $\mathrm{Ge}^{4+}$ cation reference, above) into the inner granular layer. As an anodic dissolution product of $\mathrm{Ge}$ in water, Ge-oxide formation is more thermodynamically favourable than hydroxide formation. ${ }^{33,45}$ Oxide formation via anodic dissolution is given by the following reactions: ${ }^{45}$

$\mathrm{Ge}+\mathrm{H}_{2} \mathrm{O}=\mathrm{GeO}(\mathrm{s})+2 \mathrm{H}^{+}(\mathrm{aq})+2 \mathrm{e}^{-}$

$\mathrm{Ge}+2 \mathrm{H}_{2} \mathrm{O}=\mathrm{GeO}_{2}(\mathrm{~s})+4 \mathrm{H}^{+}(\mathrm{aq})+4 \mathrm{e}^{-}$

The associated standard (equilibrium) redox potential is $-0.2 \mathrm{~V}_{\mathrm{SHE}}$ and $-0.15 V_{S H E}$ for Equation 6 and 7 , respectively. Equation 7 is the predominant anodic oxide formation reaction in alkaline solutions ${ }^{33,45,46}$ or in the presence of a strong oxidizing agent, such as $\mathrm{H}_{2} \mathrm{O}_{2}(a q)^{47}$. Enhanced dissolution of $\mathrm{Ge}$ in alkaline solutions has been ascribed to the increased solubility of the $\mathrm{GeO}(\mathrm{OH})_{3}{ }^{-}$(aq) anion as a dissolution product. ${ }^{48,49}$ Dissolution is a two-step process, involving the initial formation of neutral $\mathrm{Ge}(\mathrm{OH})_{4}(\mathrm{aq})$ as a dissolved dissolution product of $\mathrm{GeO}_{2}$ and the subsequent dissociation of neutral $\mathrm{Ge}(\mathrm{OH})_{4}(\mathrm{aq})$, as given by the following reactions: ${ }^{49}$

$$
\begin{aligned}
& \mathrm{GeO}_{2}(\mathrm{~s})+2 \mathrm{H}_{2} \mathrm{O}=\mathrm{Ge}(\mathrm{OH})^{0}{ }_{4}(\mathrm{aq}) \\
& \mathrm{Ge}(\mathrm{OH})^{0}{ }_{4}=\mathrm{GeO}(\mathrm{OH})^{-}{ }_{3}(\mathrm{aq})+\mathrm{H}^{+}(\mathrm{aq})
\end{aligned}
$$

The associated solubility product $\left(\mathrm{K}_{\mathrm{sp}}\right)$ values, measured at $25{ }^{\circ} \mathrm{C}$, are 5.02 and 9.32 for Equations 8 and 9 , respectively. Thus, Ge can be incorporated into the inner $\mathrm{MgO} / \mathrm{Mg}(\mathrm{OH})_{2}$ layer during anodic dissolution as $\mathrm{Ge}, \mathrm{GeO}_{2}$ (s) or dissolved $\mathrm{Ge}(\mathrm{OH})_{4}(\mathrm{aq})$, the latter akin to $\mathrm{Cl}^{-}$(aq) inclusion. The dissolved $\mathrm{Ge}(\mathrm{OH})_{4}$ (aq) component would likely re-crystalize as $\mathrm{GeO}_{2}$ (reverse of Equation 8) upon removal (dehydration) of the specimen from solution and/or subsequent TEM specimen preparation and analysis.

An apparent weakness in this argument is the observation that pure Ge has an OCP that is significantly more noble than $\mathrm{Mg}$ in $\mathrm{NaCl}(\mathrm{aq})$, which implies that a rather strong oxidizer is required to promote anodic dissolution of $\mathrm{Ge} .33,45,46$ The anodic polarization provided by both the $\mathrm{Mg}_{2} \mathrm{Ge}$ intermetallic phase (under freely corroding conditions) and by the potentiostat (under anodic polarization conditions) is insufficient to provide the necessary driving force for anodic dissolution of Ge. However, the electrochemical activity of pure Ge discussed in this context involves the rupture of Ge-Ge bonds by solution components as a necessary step in the overall anodic dissolution reaction. Given the low addition of $\mathrm{Ge}$ in this case ( $0.3 \mathrm{wt} . \%)$, it is reasonable to consider that the rupture susceptibility of $\mathrm{Mg}$-Ge bonds by solution components may be significantly altered as a starting point for understanding. For example, unlike $\mathrm{Ge}-\mathrm{Ge}$ bonds that are nonpolar covalent, Mg-Ge bonds have an electronegativity difference of 0.7 , which make these bonds polar covalent, and thus more susceptible to attack by solution components. More research is required to better understand the electrochemical activity of $\mathrm{Ge}$ as a solute in the $\alpha-\mathrm{Mg}$ matrix.
As mentioned earlier, Figure 15 has superimposed onto it published data for a region that exhibited cathodic activation on pure $\mathrm{Mg}$ under anodic polarization at $+100 \mathrm{mV}$ vs. the OCP in $0.1 \mathrm{M} \mathrm{NaCl}(\mathrm{aq}){ }^{19}$ In this case, the film/metal interface for $\mathrm{Mg}-0.3 \mathrm{Ge}$ is defined as the position that corresponds to a $50 \%$ increase in the $\mathrm{O} / \mathrm{Mg}$ ratio from the baseline value observed in the metal. Both films are comprised of a thinner, inner granular layer and a thicker outer columnar layer. The O/Mg ratio of the inner layer formed on $\mathrm{Mg}-0.3 \mathrm{Ge}$ is larger than that formed on pure $\mathrm{Mg}$ and it is somewhat thicker. In contrast, the $\mathrm{O} / \mathrm{Mg}$ ratio of the outer layer formed on $\mathrm{Mg}-0.3 \mathrm{Ge}$ is similar to that formed on pure $\mathrm{Mg}$, but it is somewhat thinner. Direct comparison of the two profiles identifies the composition of the inner layer as being the most likely candidate for playing a key role in moderating cathodic activation. It is proposed here that the observed moderation of cathodic activation is a consequence of the incorporation of $\mathrm{Ge}$ into the inner layer during the anodic dissolution of $\mathrm{Mg}$. If true, then the more plausible cause of moderation involves the entrapped $\mathrm{Ge}$ particles and/or $\mathrm{GeO}_{2}$ serving as an effective cathode poison for $\mathrm{H}$ recombination in the overall $\mathrm{H}_{2}$ evolution reaction, ${ }^{35,36,37,38}$ which would otherwise readily occur on freshly formed $\mathrm{Mg}(\mathrm{OH})_{2}$ at the anodic dissolution site. ${ }^{24,33} \mathrm{Ge}$ has a reported exchange current density for $\mathrm{H}_{2}$ evolving of about $10^{-9} \mathrm{Acm}^{-250,51}$ coupled with a (comparatively high) $\mathrm{Ge}-\mathrm{H}$ bond strength value of $339 \mathrm{~kJ} / \mathrm{mol},{ }^{52}$ placing it near the bottom of the descending branch of the so-called "volcano plot" - i.e. where absorption is slow and the overall $\mathrm{H}_{2}$ evolution rate is limited. Figure 9 reveals that $\mathrm{H}_{2}$ evolution (cathodic activation) continued to occur during anodic dissolution of $\mathrm{Mg}-0.3 \mathrm{Ge}$. Here, the source of this cathodic activation is likely local, restricted to the site of anodic dissolution itself, which is undetectable by the SVET. ${ }^{15}$

\section{Conclusions}

Herein, SVET measurements and TEM were used to determine the role of local surface film composition and microstructure formed during anodic dissolution of $\mathrm{Mg}-\mathrm{O} .3 \mathrm{Ge}$ (wt. \%). These methods were utilized to explore the physical attributes that correlate with a decrease in the observed cathodic ( $\mathrm{H}_{2}$ evolution) kinetics, and the moderation of cathodic activation in particular. From the results presented, the following conclusions may be drawn:

1. Ge alloying of Mg has a significant inhibiting effect on the cathodic activation (both locally and remotely) exhibited by pure $\mathrm{Mg}$ during anodic dissolution in $\mathrm{NaCl}$ (aq). Under freely corroding conditions, the $\mathrm{Mg}-0.3 \mathrm{Ge}$ (wt\%) alloy withstood 90 hours of immersion in $0.1 \mathrm{M}$ $\mathrm{NaCl}$ (aq) solution without dynamic localized corrosion activity (filament-like corrosion) and associated cathodic activation, as was observed on pure $\mathrm{Mg}$ after 1.5 hours of immersion in the same electrolyte. For $\mathrm{Mg}-0.3 \mathrm{Ge}$, dynamic localized corrosion activity does occur under freely corroding conditions, as demonstrated in $\mathrm{NaCl}$ (aq) solutions with concentrations greater than $1 \mathrm{M}$. However, cathodic activation is significantly moderated, only occurring locally at the site of anodic dissolution and which is not detectable by the SVET. The SVET showed that the corroded regions in the wake of the moving anodes were electrochemically inert relative to the intact surface, which served as a homogenous, mild remote cathode. Moderation of cathodic activation under freely corroding conditions coincides with a difference in the physical appearance of the corroded regions: grey/white for $\mathrm{Mg}-0.3 \mathrm{Ge}$ (without remote cathodic activation) and dark/black for pure $\mathrm{Mg}$ (with remote cathodic activation).

2. Cathodic activation during anodic dissolution of pure $\mathrm{Mg}$ under anodic polarization conditions is also significantly inhibited by Ge alloying. The SVET showed no evidence of local cathodic activity at applied current density values of up to $+4 \mathrm{mAcm}^{-2}$. Gravimetric $\mathrm{H}_{2}$ evolution data acquired over a 2-hour period under a galvanostatic anodic polarization of $+1 \mathrm{mAcm}^{-2}$ in $0.1 \mathrm{M} \mathrm{NaCl}(\mathrm{aq}$ ) indicates a $73 \%$ 
reduction in the global quantity of $\mathrm{H}_{2}$ evolved from $\mathrm{Mg}-0.3 \mathrm{Ge}$ relative to pure $\mathrm{Mg}$.

3. Moderation of cathodic activation by alloyed Ge was determined herein to be associated with the incorporation of $\mathrm{Ge}$ into the inner $\mathrm{MgO} / \mathrm{Mg}(\mathrm{OH})_{2}$ layer during anodic dissolution of $\mathrm{Mg}$. Such entrapped $\mathrm{Ge}$ particles, in addition to $\mathrm{GeO}_{2}$, may serve as an effective poison for $\mathrm{H}$ recombination in the overall $\mathrm{H}_{2}$ evolution reaction that would otherwise readily occur on freshly formed $\mathrm{Mg}(\mathrm{OH})_{2}$ at the anodic dissolution site.

\section{List of symbols}

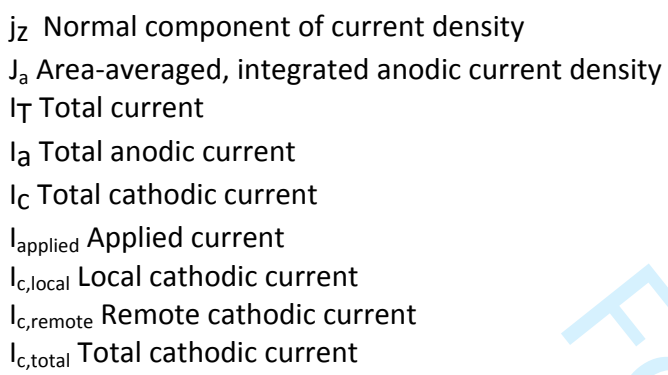

\section{Acknowledgements}

Financial support was provided by the Natural Sciences and Engineering Research Council of Canada (NSERC). The Canadian Centre for Electron Microscopy is a national facility supported by NSERC, the Canada Foundation for Innovation (CFI) and McMaster University. Financial support was also provided by Innovate UK for the SPECIFIC Innovation and Knowledge Centre (grant numbers EP/I019278/1, EP/K000292/1, EP/L010372/1).

\section{Figure Captions}

Figure 1. (a.i) Surface map showing normal current density $\left(j_{z}\right)$ distributions above pure $\mathrm{Mg}$ after 9 hours of immersion in $0.1 \mathrm{M} \mathrm{NaCl}$ (aq) solution. (a.ii) Image showing corresponding surface appearance after 24 hours of immersion. (b.i.) Surface map showing normal current density $\left(\mathrm{j}_{\mathrm{z}}\right)$ distributions above $\mathrm{Mg}-0.3 \mathrm{Ge}$ at 9 hours immersion in $0.1 \mathrm{M}$ $\mathrm{NaCl}$ (aq) solution. (b.ii) Image showing corresponding surface appearance after 90 hours of immersion.

Figure 2. SVET-derived integrated anodic current density values $\left(J_{a}\right)$ as a function of time for pure $\mathrm{Mg}$ and $\mathrm{Mg}-0.3 \mathrm{Ge}$ immersed in $0.1 \mathrm{M} \mathrm{NaCl}$ (aq) solution.

Figure 3. SVET-derived integrated anodic current density values $\left(J_{a}\right)$ as a function of time for $\mathrm{Mg}-0.3 \mathrm{Ge}$ immersed in $\mathrm{NaCl}$ (aq) solution at concentrations of $0.1 \mathrm{M}, 0.5 \mathrm{M}, 1 \mathrm{M}$ and $5 \mathrm{M}$.

Figure 4. (a) Surface map showing normal current density $\left(j_{z}\right)$ distributions above pure $\mathrm{Mg}$ after immersion in $2 \mathrm{M} \mathrm{NaCl}$ (aq) at times (i) 7 hours, (ii) 14 hours and (iii) 17 hours. (iv) Image showing corresponding surface appearance after 17 hours of immersion. (b) Surface map showing normal current density $\left(\mathrm{j}_{\mathrm{z}}\right)$ distributions above $\mathrm{Mg}$ $0.3 \mathrm{Ge}$ after immersion in $2 \mathrm{M} \mathrm{NaCl}$ (aq) solution at times (i) 3.8 hours, (ii) 7.6 hours and (iii) 7.9 hours. (iv) Imaging showing corresponding surface appearance after 9 hours immersion.

Figure 5. OCP transients for pure $\mathrm{Mg}$ immersed in $2 \mathrm{M} \mathrm{NaCl}$ (aq) solution and for $\mathrm{Mg}-0.3 \mathrm{Ge}$ immersed in $2 \mathrm{M}$ and $1 \mathrm{M} \mathrm{NaCl}(\mathrm{aq})$ solution.
Figure 6. Part $\mathrm{i}$ shows normal current density $\left(\mathrm{j}_{2}\right)$ distribution maps above pure $\mathrm{Mg}$ after 76 min of immersion in $0.1 \mathrm{M} \mathrm{NaCl}$ (aq) solution held under galvanostatic anodic polarization at (a) $+1 \mathrm{mAcm}^{-2},(\mathrm{~b})+2$ $\mathrm{mAcm}^{-2}$ and (c) $+4 \mathrm{mAcm}^{-2}$. Part ii shows photographic images of the corresponding surface appearance after $76 \mathrm{~min}$.

Figure 7. Time dependent SVET-derived integrated current $\left(I_{a}\right.$ and $\left.I_{c}\right)$ normalized for a $1 \mathrm{~cm}^{2}$ area of pure $\mathrm{Mg}$ and $\mathrm{Mg}-0.3 \mathrm{Ge}$ held under galvanostatic anodic polarization at $+1 \mathrm{mAcm}^{-2}$ in $0.1 \mathrm{M} \mathrm{NaCl}$ (aq) solution.

Figure 8. Parts $i$ and ii shows normal current density $\left(j_{2}\right)$ distributions maps above Mg-0.3Ge after 0.5 hours and 2 hours of immersion in 0.1 $\mathrm{M} \mathrm{NaCl}(\mathrm{aq})$ solution held under galvanostatic anodic polarization at (a) $+1 \mathrm{mAcm}^{-2}$ (b) $+2 \mathrm{mAcm}^{-2}$ and (c) $+4 \mathrm{mAcm}^{-2}$. Part iii gives photographic images of the corresponding surface appearance after 3 hours of immersion.

Figure 9. Moles of $\mathrm{H}_{2}$ evolved vs. time for $\mathrm{Mg}-0.3 \mathrm{Ge}$ under galvanostatic anodic polarization at $+4 \mathrm{mAcm}^{-2},+2 \mathrm{mAcm}^{-2}$ and $+1 \mathrm{mAcm}^{-2}$ while immersed in $0.1 \mathrm{M} \mathrm{NaCl}(\mathrm{aq})$ solution. The dashed line represents the total $\mathrm{H}_{2}$ evolved from pure $\mathrm{Mg}$ after 2 hours immersed in the same conditions while under galvanostatic anodic polarization at $+1 \mathrm{~mA} \mathrm{~cm}^{-2}$.

Figure 10. Secondary electron image (SEI) of the exposed Mg-0.3Ge surface showing a typical appearance (a) after 1 hour of conditioning at the OCP in $0.01 \mathrm{M} \mathrm{NaCl}$ (aq) solution and (b) after an additional potentiostatic anodic polarization at $+100 \mathrm{mV}$ more positive than the OCP for 30 minutes. The superimposed lines on image (b) identify the regions from which FIB-prepared cross-sectional specimens for subsequent TEM examination were extracted.

Figure 11. Cross-sectional bright field image, and associated SAD patterns, of the surface film formed on the centre region of a Mg-0.3Ge grain ( $\alpha-\mathrm{Mg}$ matrix phase) after potentiostatic anodic polarization in $0.01 \mathrm{M} \mathrm{NaCl}(\mathrm{aq})$ solution for 30 minutes.

Figure 12. Cross-sectional bright field image, and associated SAD patterns, of the surface film formed on the preferentially dissolved $\mathrm{Mg}$ $0.3 \mathrm{Ge}$ grain boundary region after potentiostatic anodic polarization in $0.01 \mathrm{M} \mathrm{NaCl}(\mathrm{aq})$ solution for 30 minutes.

Figure 13. HAADF-STEM dark field image and an associated set of EDS maps of the film formed on $\alpha-M g$ matrix phase away from grain boundary after potentiostatic anodic polarization in $0.01 \mathrm{M} \mathrm{NaCl}(\mathrm{aq})$ solution for 30 minutes.

Figure 14. Ge (at.\%) depth profile across the inner/outer layers using the STEM-EDS data in the elemental maps shown in Figure 13.

Figure 15. $\mathrm{O} / \mathrm{Mg}$ atomic ratio as a depth profile across the metal/film interface using the STEM-EDS data in the elemental maps shown in Figure 13. Superimposed onto the plot is a similar data set for pure $\mathrm{Mg}$ under similar anodic polarization consitions. ${ }^{19}$ 


\section{References}

1. W.J. Joost, P.E. Krajewski, Scr. Mater. 128 (2017): p. 107.

2. W.A. Monteiro, "The influence of alloy element on magnesium for electronic devices applications-a review," in Light Metal Alloys Applications, ed. W.A. Monterio (Intech Open, 2014) p. 229.

3. T. B. Abbott, Corrosion 71, (2015): p. 120.

4. M. Esmaily, J.E. Svensson, S. Fajardo, N. Birbilis, G.S. Frankel, S. Virtanen, R. Arrabal, S. Thomas, L. G. Johansson, Prog. Mater. Sci. 89 (2017): p. 92.

5. R.L. Liu, M.F. Hurley, A. Kvryan, G. Williams, J.R. Scully, N. Birbilis, Sci. Rep. 6 (2016): p. 28747.

6. R. L. Liu, J.R. Scully, G. Williams, N. Birbilis, Electrochim. Acta 260 (2018): p. 184.

7. J.A. Yuwono, N. Birbilis, R.L. Liu, Q. Ou, Q. Bao, N.V. Medhekarz, J. Electrochem. Soc. 164 (2017): p. C918.

8. A. Maltseva, V. Shkirskiy, G. Lefèvre, P. Volovitch, Corros. Sci. 153 (2019): p. 272.

9. I. Lambert, H.L. Clever (Eds.), "Alkaline Earth Hydroxides in Water and Aqueous Solutions," IUPAC Solubility Data Series, Vol. 52 (Oxford, UK: Pergamon Press, 1992), p. 104.

10. G. Williams, Geraint, H.N. McMurray, J. Electrochem. Soc. 155 (2008): p. C340.

11. G. Williams, N. Birbilis, H.N. McMurray, Electrochem. Commun. 36 (2013): p. 1.

12. G. Williams, N. Birbilis, H.N. McMurray, Faraday Discuss. 180 (2015): p. 313.

13. S. Fajardo, C.F. Glover, G. Williams, G.S. Frankel, Electrochim. Acta 212 (2016): p. 510.

14. S. Fajardo, C.F. Glover, G. Williams, G. S. Frankel, Corrosion 73 (2017): p. 482.

15. E. Michailidou, H.N. McMurray, G. Williams, J. Electrochem. Soc. 165 (2018): p. C195.

16. N. Birbilis, A.D. King, S. Thomas, G.S. Frankel, J.R. Scully, Electrochim. Acta 132 (2014): p. 277.

17. S. Thomas, N.V. Medhekar, G.S. Frankel, N. Birbilis, Curr. Opin. Solid State Mater. Sci. 19 (2015): p. 85.

18. G.S. Frankel, A. Samaniego, N. Birbilis, Corros. Sci. 70 (2013): p. 104.

19. M. Taheri, J.R. Kish, N. Birbilis, M. Danaie, E.A. McNally, J.R. McDermid, Electrochim. Acta 116 (2014): p. 396.

20. T. Cain, S.B. Madden, N. Birbilis, J.R. Scully, J. Electrochem. Soc. 162 (2015): p. C228.

21. N. Birbilis, T. Cain, J.S. Laird, X. Xia, J.R. Scully, A.E. Hughes, ECS Electrochem. Lett. 4 (2015): p. C34.

22. D. Hoche, C. Blawert, S.V. Lamaka, N. Scharnagl, C. Mendis, M.L. Zheludkevich, J. Chem. Soc. Faraday Trans. 18 (2016): p. 1279.

23. J. Li, W. Sun, B. Hurley, A.A. Luo, R.G. Buchheit, Corros. Sci. 112 (2016): p. 760.

24. S.H. Salleh, S. Thomas, J.A. Yuwono, K. Venkatesan, N. Birbilis, Electrochim. Acta 161 (2015): p. 144.

25. W.J. Binns, F. Zargarzadah, V. Dehnavi, J. Chen, J.J. Noël, D.W. Shoesmith, Corrosion 75 (2019): p. 58.

26. B. Kim, K. Park, H. Kimura, Y. Park, I. Park, Mater. Trans. 53 (2012): p. 240.
27. D. Bian, Dong, W. Zhou, J. Deng, Y. Liu, W. Li, X. Chu, P. Xiu, H. Cai, Y. Kou, B. Jiang, Y. Zheng, Acta Biomater. 64 (2017): p. 421.

28. R.L. Liu, Z.R. Zeng, J.R. Scully, G. Williams, N. Birbilis, Corros. Sci. 140 (2018): p. 18.

29. P. Jiang, C. Blawert, R. Hou, N. Scharnagl, J. Bohlen, M.L. Zheludkevich, J. Alloys Compd. 783 (2019): p. 179.

30. G. Williams, H.A.-L. Dafydd, H.N. McMurray, N. Birbilis, Electrochim. Acta 219 (2016): p. 401.

31. N. Birbilis, G. Williams, K. Gusieva, A. Samaniego, M.A. Gibson, H.N. McMurray, Electrochem. Commun. 34 (2013): p. 295.

32. D. Eaves, G. Williams, H. N. McMurray, Electrochim. Acta 79 (2012): p. 1

33. R.L. Liu, S. Thomas, J.R. Scully, G. Williams, N. Birbilis, Corrosion 73 (2017): p. 494.

34. S. Thomas, O. Gharbi, S.H. Salleh, P. Volovitch, K. Ogle, N. Birbilis, Electrochim. Acta 210 (2016): p. 271

35. B.E. Conway, B.V. Tilak, Adv. Catal. 38 (1992): p.1

36. B.E. Conway, G. Jerkiewicz, J. Electroanal. Chem. 357 (1993): p. 47.

37. J.M. Jaksic, N.M. Ristic, N.V. Krstajic, M.M. Jaksic, Int. J. Hydrog. Energy 23 (1998): p. 1121.

38. S.Y. Qian, B.E. Conway, G. Jerkiewicz, J. Chem. Soc. Faraday Trans. 94 (1998): p. 2945.

39. T.W. Cain, C.F. Glover, J.R. Scully, Electrochim. Acta 297 (2019): p. 564.

40. C.P. Cano, M. Danaie, J.R. Kish, J.R. McDermid, G.A. Botton, G. Williams, Corrosion 71 (2015): p. 146.

41. Z.P. Cano, J.R. McDermid, J.R. Kish, J. Electrochem. Soc. 162 (2015): p. C732.

42. G. Williams, A.J. Coleman, H.N. McMurray, Electrochim. Acta 55 (2010): p. 5947.

43. G. Williams, H.A.-L. Dafydd, R. Subramanian, H.N. McMurray, Corrosion 73 (2017): p. 471.

44. G. Williams, H.A.-L. Dafydd, R. Subramanian, H.N. McMurray, Corrosion 73 (2017): p. 471.

45. M. Pourbaix, Atlas of Electrochemical Equilibria in Aqueous Solutions, 2nd ed. (Houston, TX: NACE International, 1974).

46. Y-F. Niu, J-P. Guin, T. Rouxel, A. Abdelouas, J. Troles, F.F. Smektala, J. Am. Ceram. Soc., 92 (2009): p. 1779.

47. L. Zhang, B. Zhang, B. Pan, C. Wang, Appl. Surf. Sci. 422 (2017): p. 247.

48. C.F. Baes Jr., R.E. Mesmer, The Hydrolysis of Cations (New York, NY, John Wiley \& Sons, 1976).

49. G.S. Pokrovski, J. Schott, Geochim. Cosmochim. Acta 62 (1998): p. 1631.

50. S. Trasatti, J. Electroanal. Chem. Interfacial Electrochem. 39 (1972): p. 163.

51. S. Trasatti, "Electrocatalysis of Hydrogen Evolution: Progress in Cathode Activation," in Advances in Electrochemical Science \& Engineering, Vol. 2, H. Gerischer, C. Tobias, eds. (New York, NY, VCH Publishers Inc., 1992): pp. 1-86.

52. M.J. Almond, A.M. Doncaster, P.N. Noble, R. Walsh, J. Amer. Chem. Soc. 104 (1982): p. 4717. 

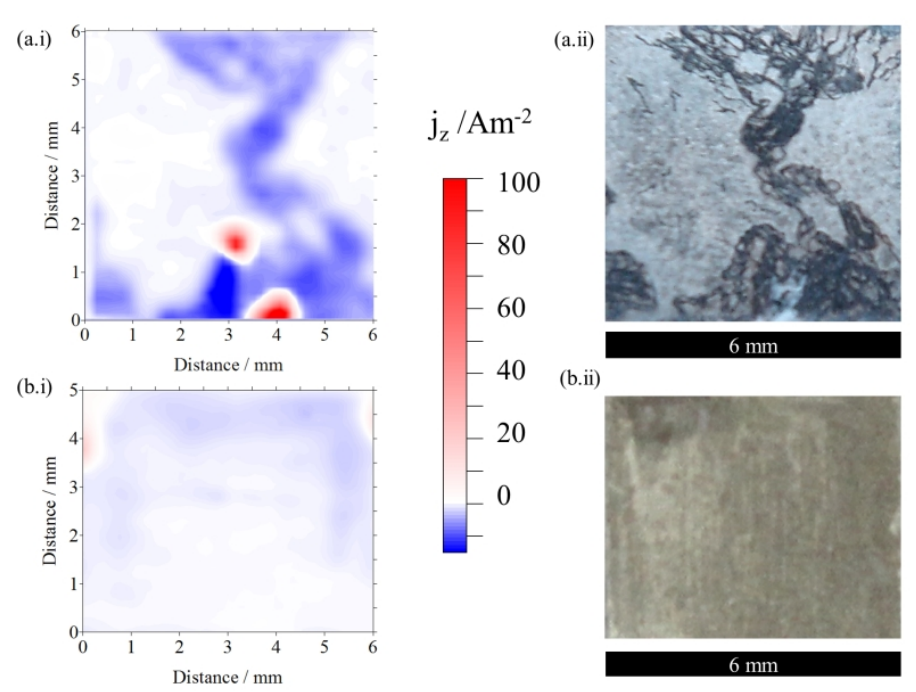

(a.i) Surface map showing normal current density $\left(j_{z}\right)$ distributions above pure $\mathrm{Mg}$ after 9 hours of immersion in $0.1 \mathrm{M} \mathrm{NaCl}$ (aq) solution. (a.ii) Image showing corresponding surface appearance after 24 hours of immersion. (b.i.) Surface map showing normal current density $\left(j_{z}\right)$ distributions above $\mathrm{Mg}-0.3 \mathrm{Ge}$ at 9 hours immersion in $0.1 \mathrm{M} \mathrm{NaCl}(\mathrm{aq})$ solution. (b.ii) Image showing corresponding surface appearance after 90 hours of immersion.

$254 \times 190 \mathrm{~mm}(300 \times 300$ DPI) 


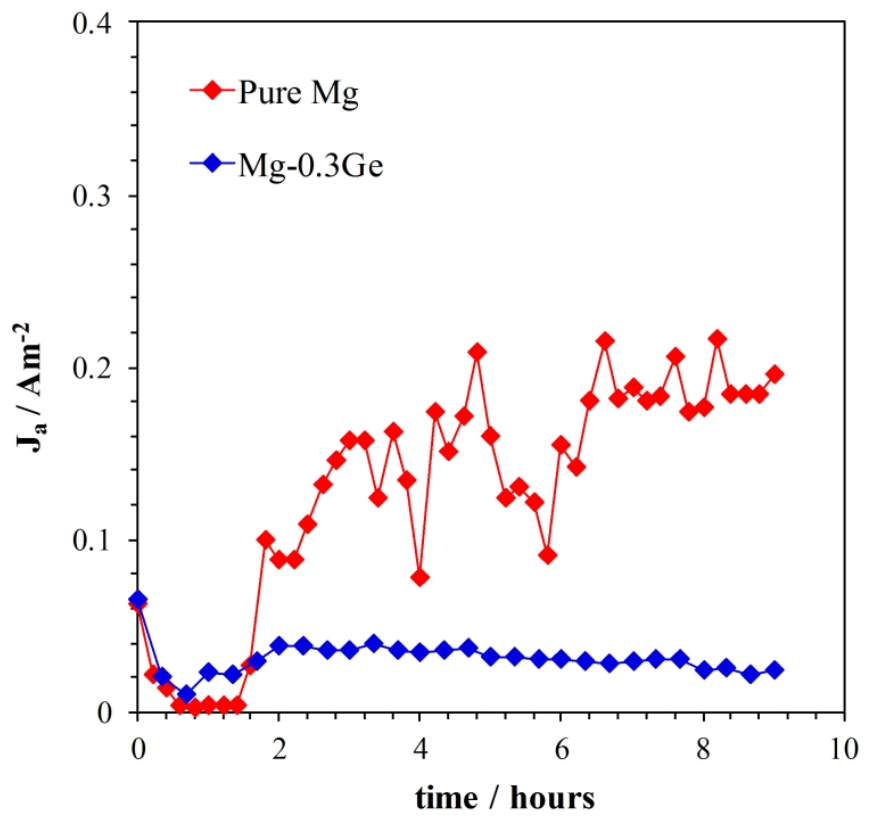

SVET-derived integrated anodic current density values $\left(\mathrm{J}_{\mathrm{a}}\right)$ as a function of time for pure $\mathrm{Mg}$ and $\mathrm{Mg}-0.3 \mathrm{Ge}$ immersed in $0.1 \mathrm{M} \mathrm{NaCl}(\mathrm{aq})$ solution.

$254 \times 190 \mathrm{~mm}(300 \times 300 \mathrm{DPI})$ 
SVET-derived integrated anodic current density values $\left(\mathrm{J}_{\mathrm{a}}\right)$ as a function of time for $\mathrm{Mg}-0.3 \mathrm{Ge}$ immersed in $\mathrm{NaCl}$ (aq) solution at concentrations of $0.1 \mathrm{M}, 0.5 \mathrm{M}, 1 \mathrm{M}$ and $5 \mathrm{M}$. 
(a)
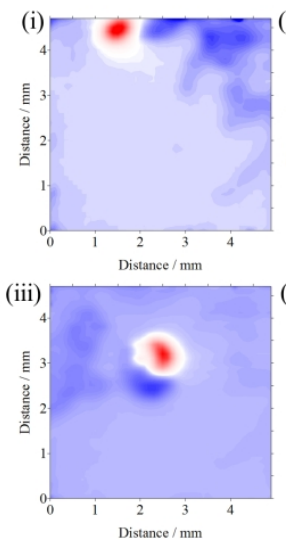
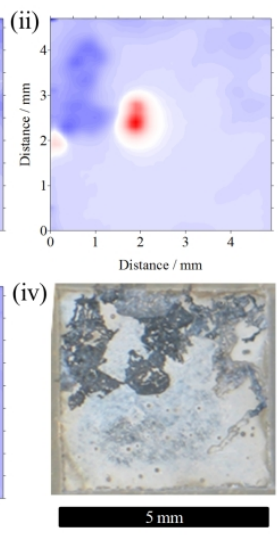

(b)
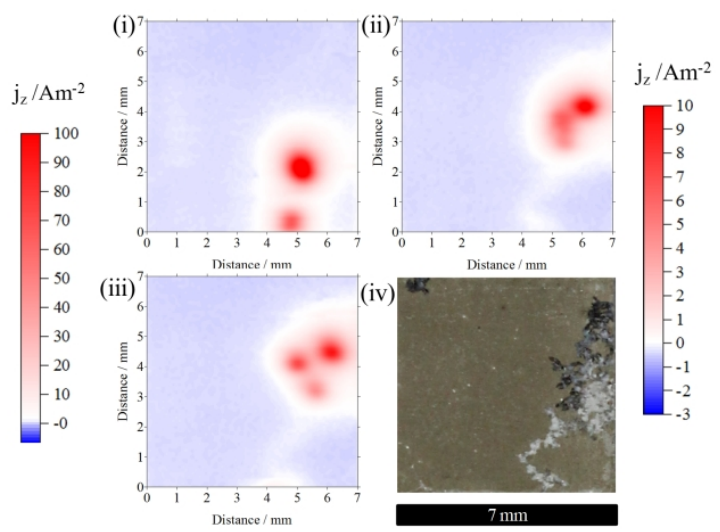

(a) Surface map showing normal current density $\left(\mathrm{j}_{\mathrm{z}}\right)$ distributions above pure $\mathrm{Mg}$ after immersion in $2 \mathrm{M}$ $\mathrm{NaCl}$ (aq) at times (i) 7 hours, (ii) 14 hours and (iii) 17 hours. (iv) Image showing corresponding surface appearance after 17 hours of immersion. (b) Surface map showing normal current density $\left(\mathrm{j}_{\mathrm{z}}\right)$ distributions above $\mathrm{Mg}-0.3 \mathrm{Ge}$ after immersion in $2 \mathrm{M} \mathrm{NaCl}$ (aq) solution at times (i) 3.8 hours, (ii) 7.6 hours and (iii) 7.9 hours. (iv) Image showing corresponding surface appearance after 10.59 hours immersion. 


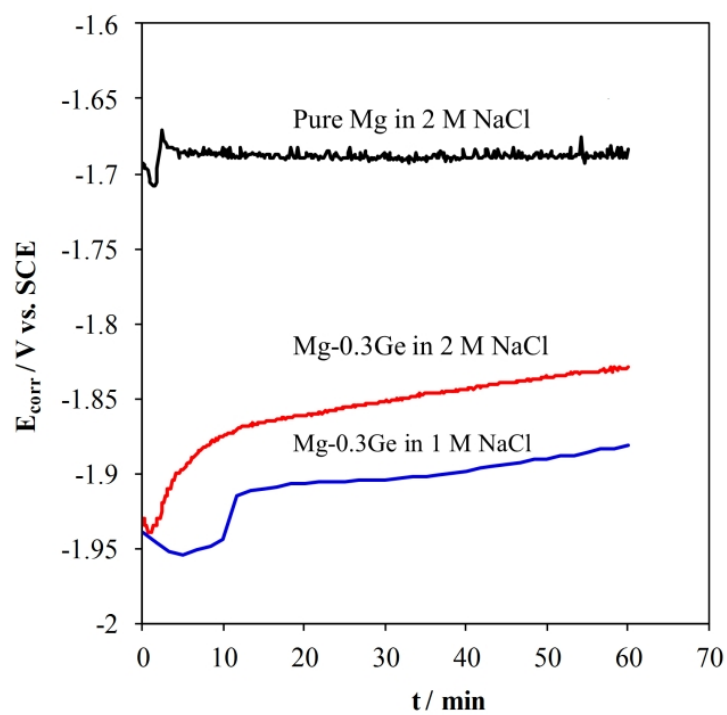

OCP transients for pure $\mathrm{Mg}$ immersed in $2 \mathrm{M} \mathrm{NaCl}(\mathrm{aq})$ solution and for $\mathrm{Mg}-0.3 \mathrm{Ge}$ immersed in $2 \mathrm{M}$ and $1 \mathrm{M}$ $\mathrm{NaCl}$ (aq) solution. 

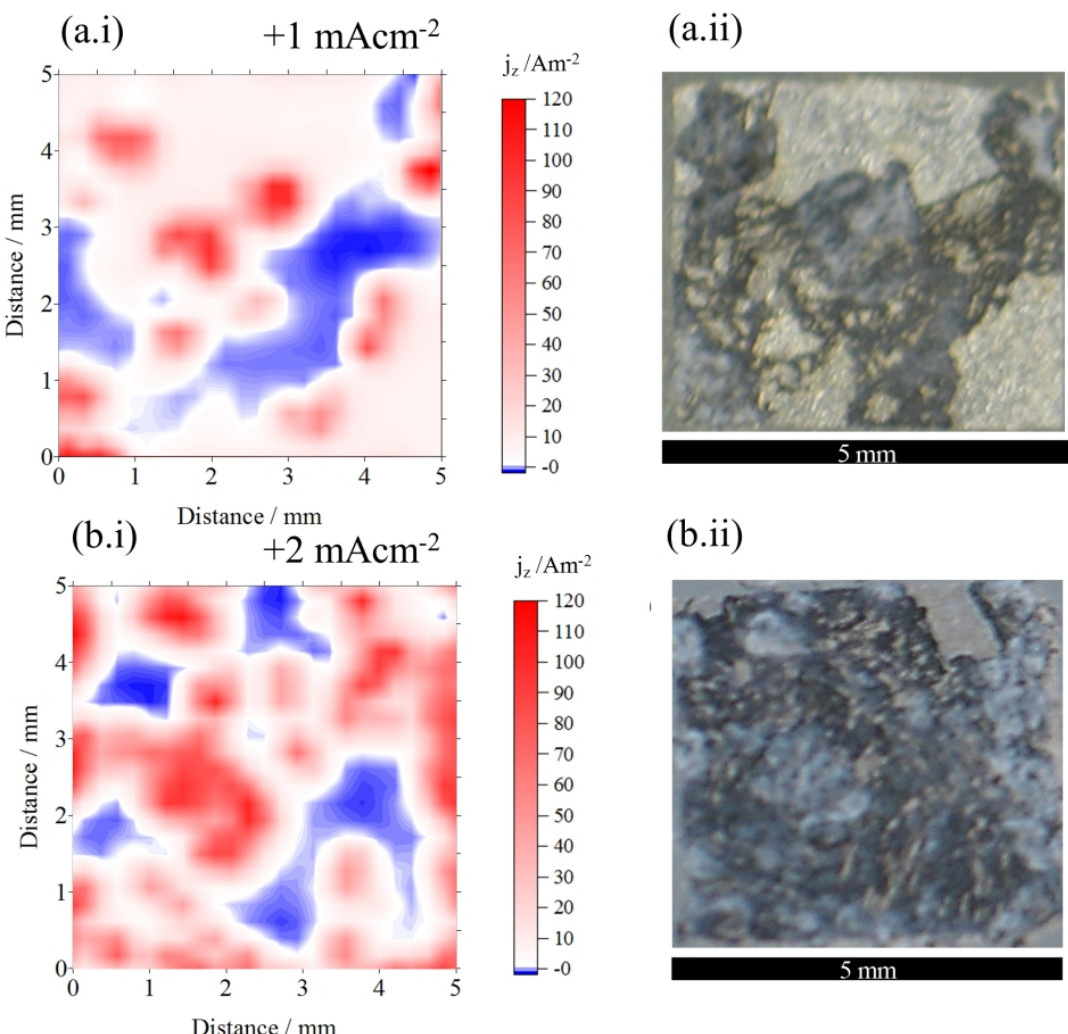

(b.ii)

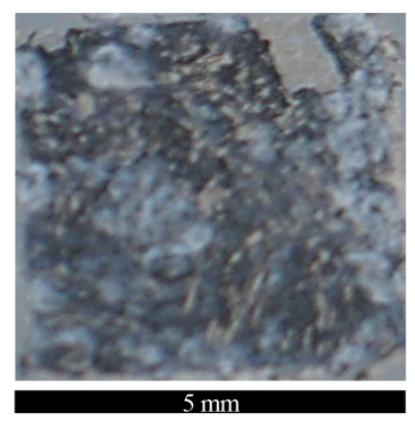

(c.i)

$+4 \mathrm{mAcm}^{-2}$

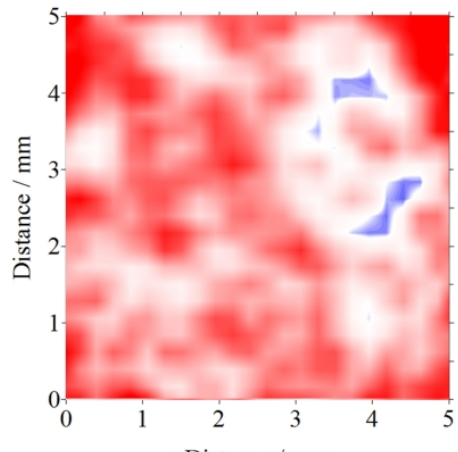

Distance / mm $\mathrm{j}_{\mathrm{z}} / \mathrm{Am}^{-2}$

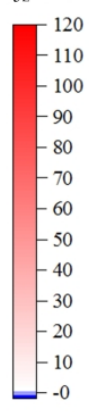

(c.ii)

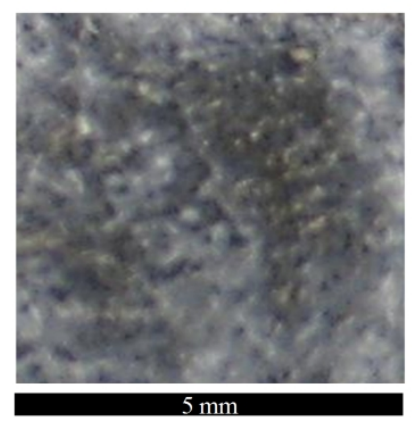

Part i shows normal current density $\left(\mathrm{j}_{\mathrm{z}}\right)$ distribution maps above pure $\mathrm{Mg}$ after 2 hours of immersion in 0.1 $\mathrm{M} \mathrm{NaCl}$ (aq) solution held under galvanostatic anodic polarization at (a) $+1 \mathrm{mAcm}^{-2}$, (b) $+2 \mathrm{mAcm}^{-2}$ and (c) $+4 \mathrm{mAcm}^{-2}$. Part ii shows photographic images of the corresponding surface appearance after 3 hours. 


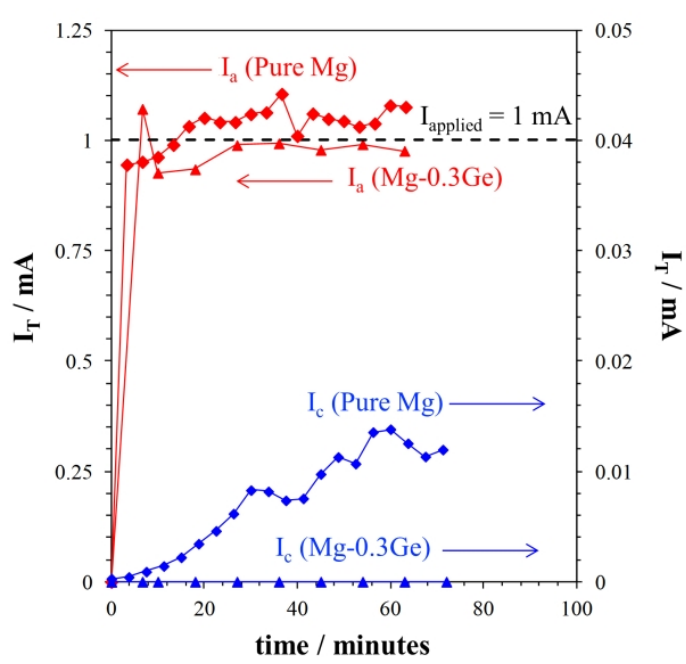

Time-dependent SVET-derived integrated current $\left(\mathrm{I}_{\mathrm{a}}\right.$ and $\mathrm{I}_{\mathrm{C}}$ ) normalizsed for a $1 \mathrm{~cm}^{2}$ area of pure $\mathrm{Mg}$ and $\mathrm{Mg}-0.3 \mathrm{Ge}$ held under galvanostatic anodic polarization at $+1 \mathrm{mAcm}^{-2}$ in $0.1 \mathrm{M} \mathrm{NaCl}$ (aq) solution.

$254 \times 190 \mathrm{~mm}(300 \times 300$ DPI $)$ 
0.5 hours

(a.i)

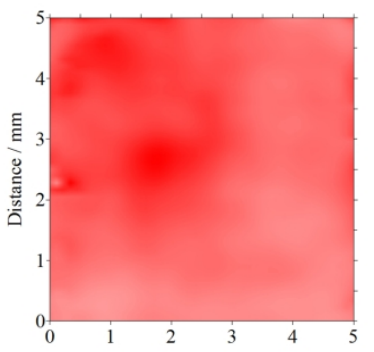

(b.i) Distance / mm

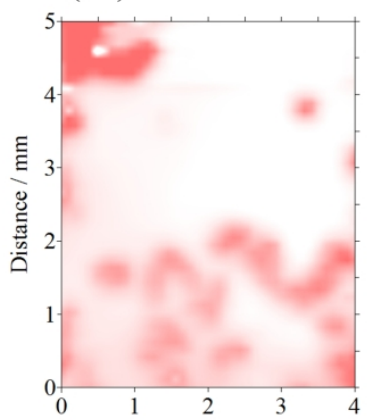

(c.i) Distance / mm

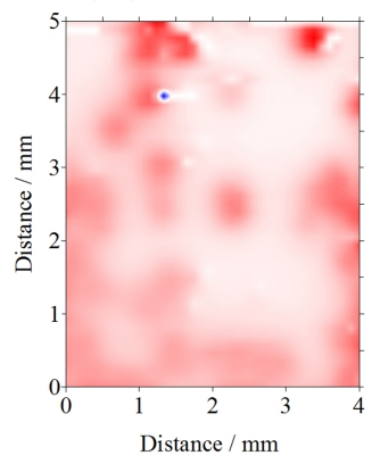

2 hours

(a.ii)

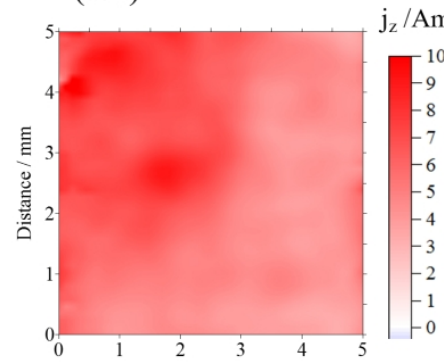

(b.ii) $)^{\text {Distance /mm }}$

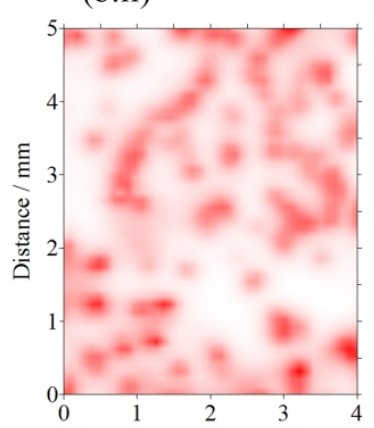

(c.ii) Distance / mm

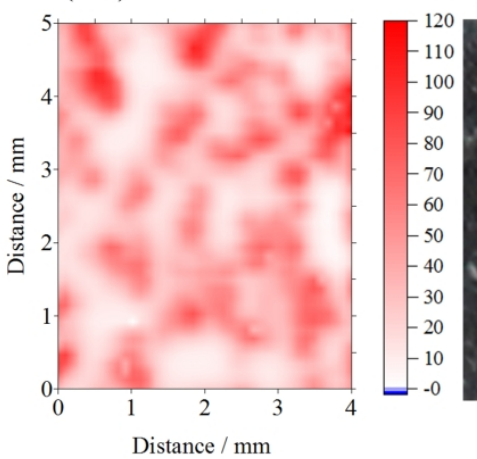

3 hours

(a.iii)

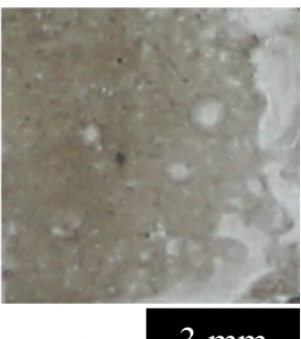

(b.iii)

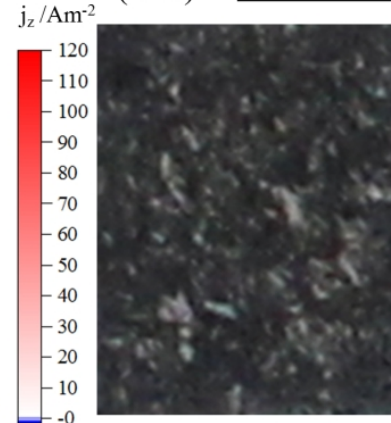

$2 \mathrm{~mm}$

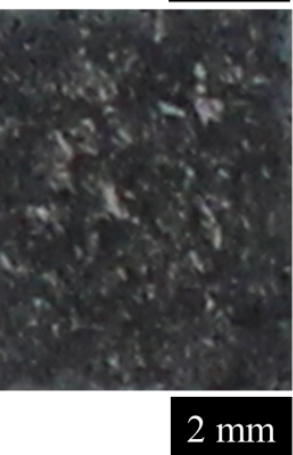

Parts $\mathrm{i}$ and ii shows normal current density $\left(\mathrm{j}_{\mathrm{z}}\right)$ distributions maps above Mg-0.3Ge after 0.5 hours and 2 hours of immersion in $0.1 \mathrm{M} \mathrm{NaCl}(\mathrm{aq})$ solution held under galvanostatic anodic polarization at (a) +1 $\mathrm{mAcm}^{-2},(\mathrm{~b})+2 \mathrm{mAcm}^{-2}$ and (c) $+4 \mathrm{mAcm}^{-2}$. Part iii gives photographic images of the corresponding surface appearance after 3 hours of immersion. 


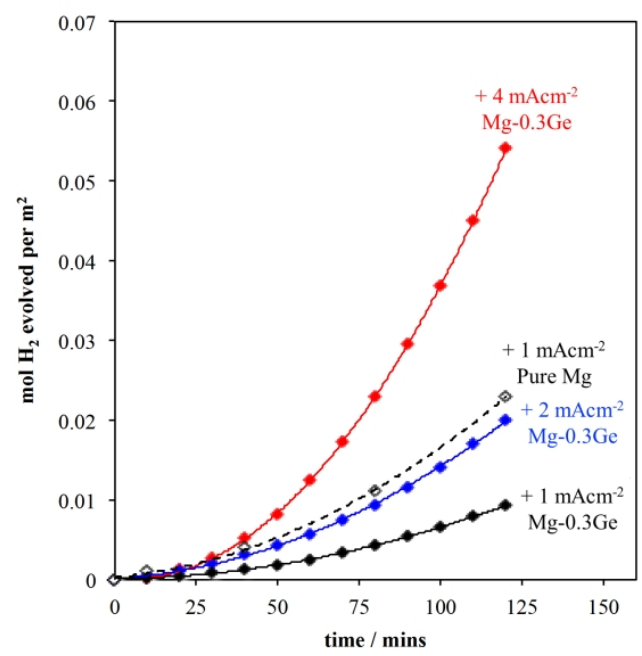

Moles of $\mathrm{H}_{2}$ evolved vs. time for $\mathrm{Mg}-0.3 \mathrm{Ge}$ under galvanostatic anodic polarization at i) $+4 \mathrm{mAcm}^{-2}$, ii) +2 $\mathrm{mAcm}^{-2}$ and iii) $+1 \mathrm{mAcm}^{-2}$ while immersed in $0.1 \mathrm{M} \mathrm{NaCl}$ (aq) solution. The dashed line represents the total $\mathrm{H}_{2}$ evolved from pure $\mathrm{Mg}$ after 2 hours immersed in the same conditions while under galvanostatic anodic polarization at $+1 \mathrm{~mA} \mathrm{~cm}{ }^{-2}$. 

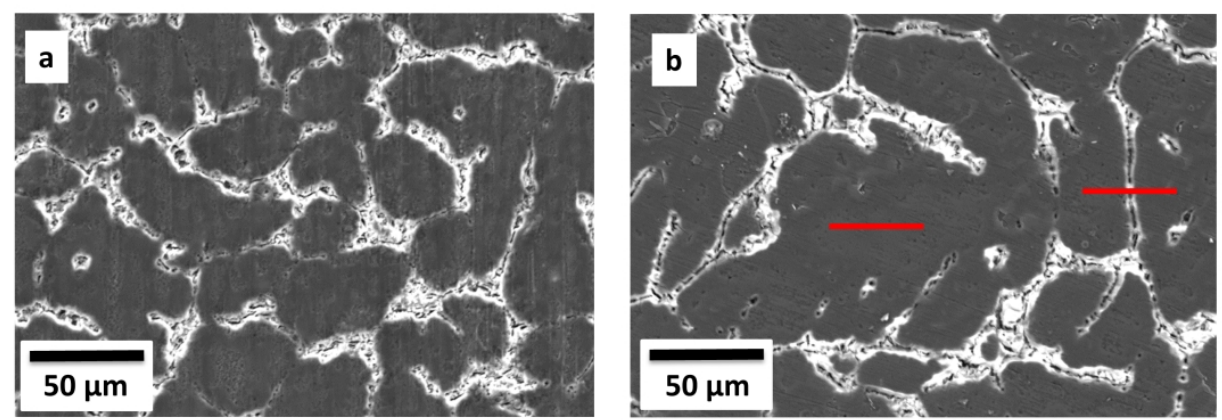

Secondary electron image (SEI) of the exposed Mg-0.3Ge surface showing a typical appearance (a) after 1 hour of conditioning at the OCP in $0.01 \mathrm{M} \mathrm{NaCl}(\mathrm{aq})$ solution and (b) after an additional potentiostatic anodic polarization at $+100 \mathrm{mV}$ more positive than the OCP for 30 minutes. The superimposed lines on image (b) identify the regions from which FIB-prepared cross-sectional specimens for subsequent TEM examination were extracted. 


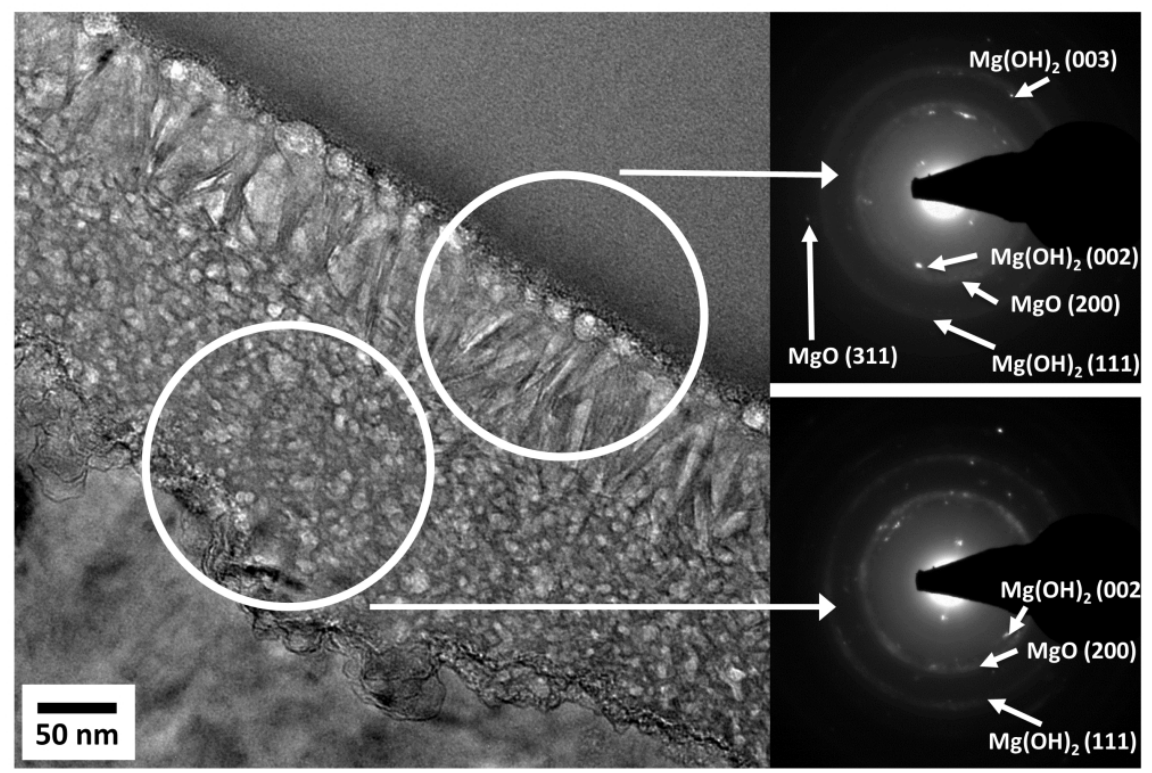

Cross-sectional bright field image, and associated SAD patterns, of the surface film formed on the center region of a $\mathrm{Mg}-0.3 \mathrm{Ge}$ grain (a-Mg matrix phase) after potentiostatic anodic polarization in $0.01 \mathrm{M} \mathrm{NaCl}(\mathrm{aq}$ ) solution for 30 minutes.

$254 \times 190 \mathrm{~mm}(300 \times 300 \mathrm{DPI})$ 


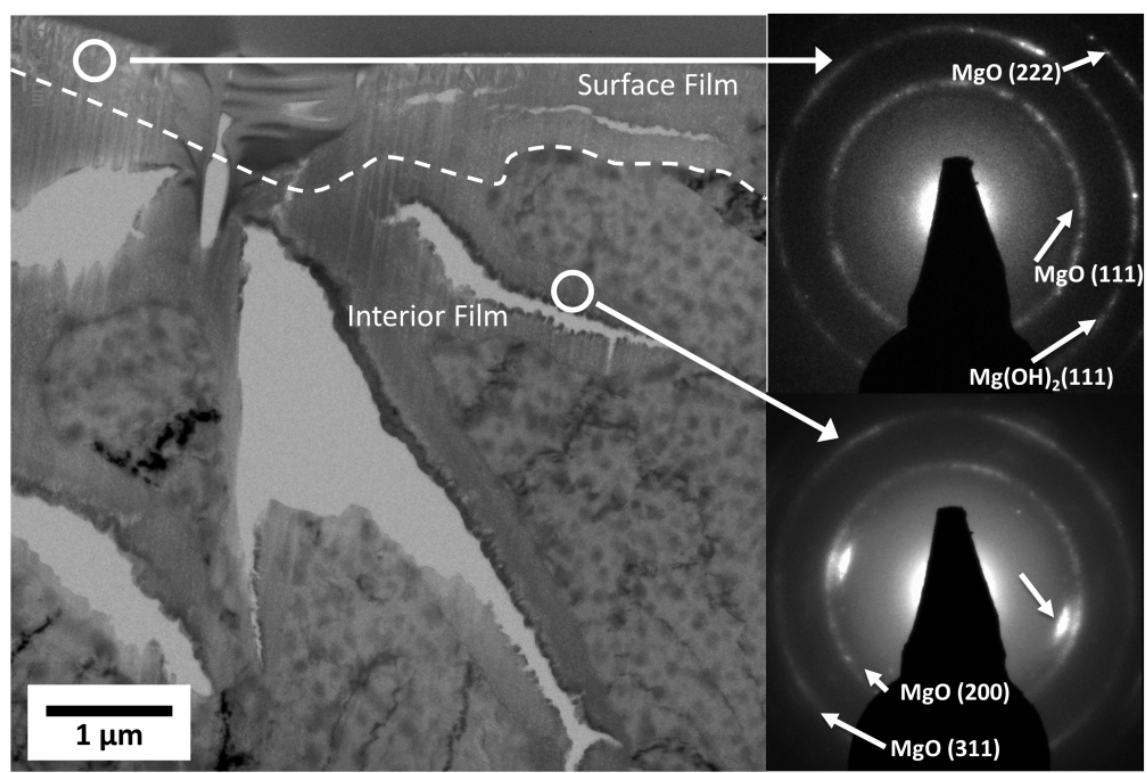

Cross-sectional bright field image, and associated SAD patterns, of the surface film formed on the preferentially dissolved $\mathrm{Mg}-0.3 \mathrm{Ge}$ grain boundary region after potentiostatic anodic polarization in $0.01 \mathrm{M}$ $\mathrm{NaCl}(\mathrm{aq})$ solution for 30 minutes. 
HAADF-STEM dark field image and an associated set of EDS maps of the film formed on a-Mg matrix phase away from grain boundary after potentiostatic anodic polarization in $0.01 \mathrm{M} \mathrm{NaCl}(\mathrm{aq})$ solution for 30 minutes. 


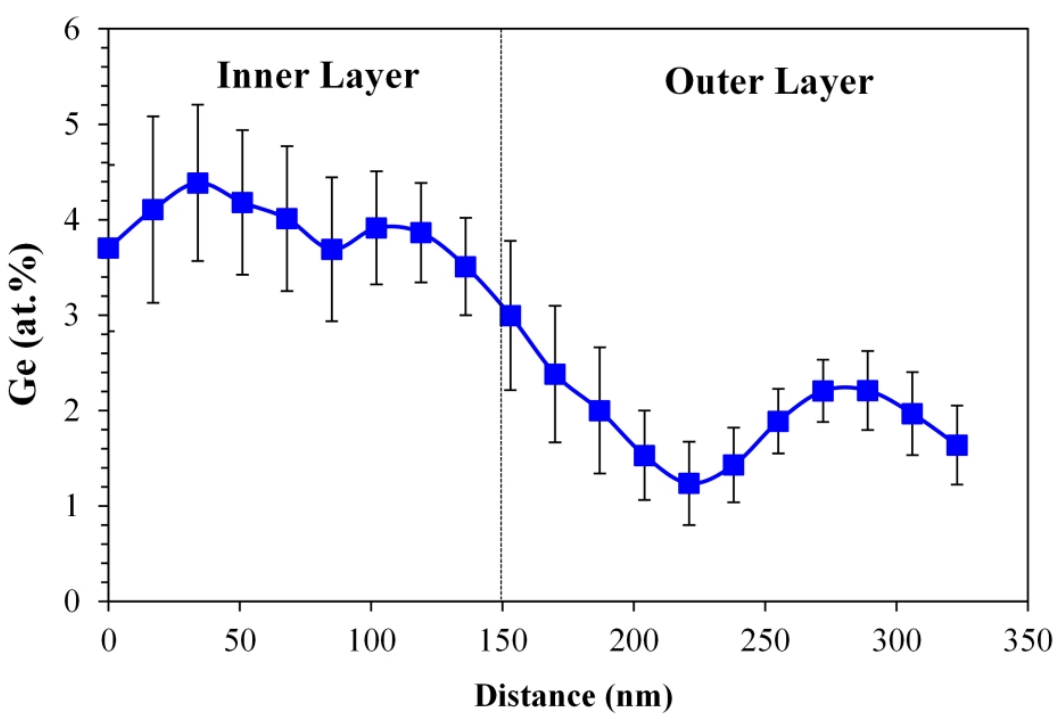

Ge (at.\%) depth profile across the inner/outer layers using the STEM-EDS data in the elemental maps shown in Figure 13.

$254 \times 190 \mathrm{~mm}(300 \times 300$ DPI) 


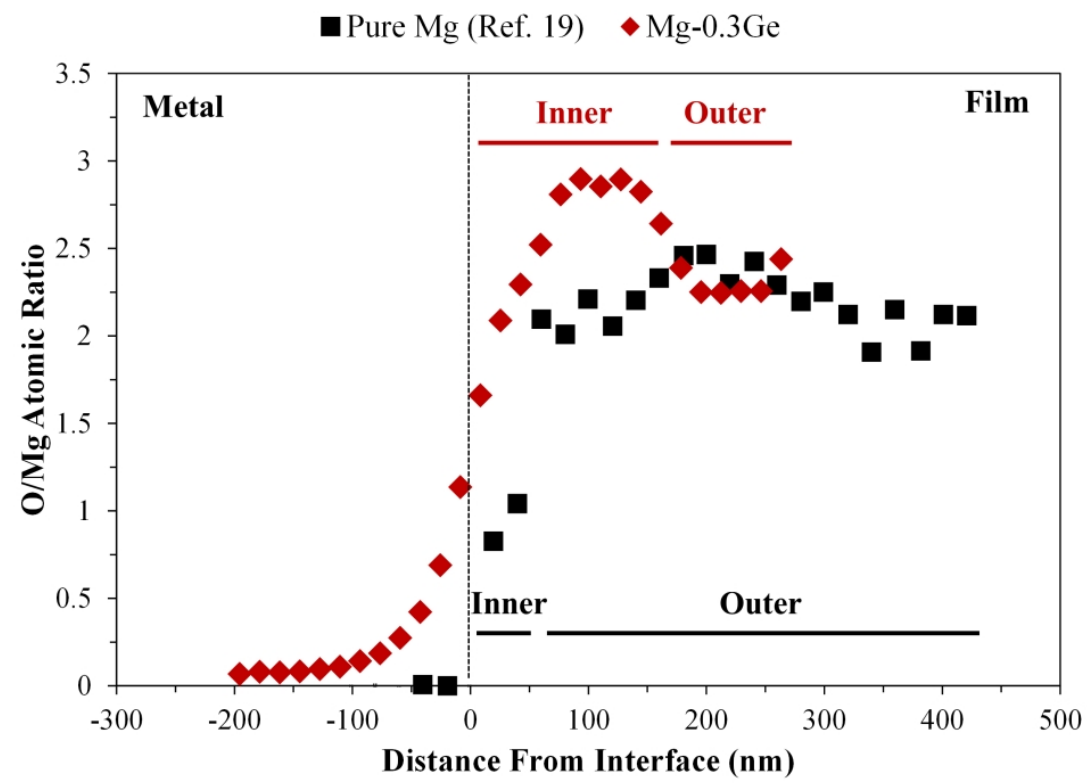

$\mathrm{O} / \mathrm{Mg}$ atomic ratio as a depth profile across the metal/film interface using the STEM-EDS data in the elemental maps shown in Figure 13. Superimposed onto the plot is a similar data set for pure $\mathrm{Mg}$ under similar anodic polarization conditions. ${ }^{19}$ 